\title{
THE
}

\section{Tropical Cyclone-Induced Thermocline Warming and Its Regional and Global Impacts}

\author{
Michael R. Bueti \\ Isaac Ginis \\ University of Rhode Island, iginis@uri.edu \\ Lewis M. Rothstein \\ University of Rhode Island, Irothstein@uri.edu \\ Stephen M. Griffies
}

Follow this and additional works at: https://digitalcommons.uri.edu/gsofacpubs

Terms of Use

All rights reserved under copyright.

\section{Citation/Publisher Attribution}

Michael R. Bueti, Isaac Ginis, Lewis M. Rothstein, and Stephen M. Griffies, 2014: Tropical

Cyclone-Induced Thermocline Warming and Its Regional and Global Impacts. J. Climate, 27, 6978-6999.

Available at: http://dx.doi.org/10.1175/JCLI-D-14-00152.1

This Article is brought to you for free and open access by the Graduate School of Oceanography at DigitalCommons@URI. It has been accepted for inclusion in Graduate School of Oceanography Faculty Publications by an authorized administrator of DigitalCommons@URI. For more information, please contact digitalcommons-group@uri.edu. 


\title{
Tropical Cyclone-Induced Thermocline Warming and Its Regional and Global Impacts
}

\author{
Michael R. Bueti, IsAaC Ginis, AND Lewis M. RothSTEIN \\ Graduate School of Oceanography, University of Rhode Island, Narragansett, Rhode Island \\ STEPHEN M. GRIFFIES \\ National Oceanographic and Atmospheric Administration/Geophysical Fluid Dynamics Laboratory, Princeton, New Jersey
}

(Manuscript received 28 February 2014, in final form 5 June 2014)

\begin{abstract}
Strong surface winds of a hurricane locally cool the surface and warm the subsurface waters via turbulent mixing processes. While the surface cool anomalies generally decay in roughly a month, the warm subsurface anomalies can persist over a seasonal cycle. The authors examine questions related to the magnitude and cumulative footprint of subsurface warm anomalies forced by tropical cyclones during the combined global tropical cyclone seasons, making use of a global ocean model forced by tropical cyclones.

Simulations of the 2004/05 tropical cyclone season are conducted with and without tropical cyclone wind forcing, blended with the daily Coordinated Ocean-Ice Reference Experiments (COREs) atmospheric state. Physical characteristics of cyclone-forced surface and subsurface anomalies are elucidated. In particular, the spatial extent and magnitude of tropical cyclone-forced subsurface warm anomalies over the course of an entire season are examined. This analysis permits the estimation of the contribution of cyclone-induced anomalies to the ocean heat content and sea surface temperature, aiding in understanding anomalous meridional heat transport.

Globally, there is a maximum accumulated heat uptake $4.1 \times 10^{21} \mathrm{~J}$, with the greatest regional contributions in the North Atlantic $\left(1.7 \times 10^{21} \mathrm{~J}\right)$, west Pacific $\left(1.5 \times 10^{21} \mathrm{~J}\right)$, and east Pacific $\left(1.7 \times 10^{21} \mathrm{~J}\right)$. An export of heat from the subtropics to the tropics via rapid advective pathways is found, most notably in the west Pacific. These warm anomalies tend to remain in the equatorial band, with potential implications for the tropical climate system.
\end{abstract}

\section{Introduction}

Tropical cyclones (TCs) are highly coherent, intermittent, and intense wind and precipitation events, notable for their ability to induce strong vertical oceanic mixing over the course of their lifetime. TCs are defined by their cyclonic winds, which increase from nearly zero to magnitudes exceeding $70 \mathrm{~m} \mathrm{~s}^{-1}$ at a radius of maximum wind on the order of $50 \mathrm{~km}$ before decreasing over several hundred kilometers. Strong sea surface temperature (SST) cooling associated with TC passage over the ocean produces a well-understood cold wake due to vertical mixing of mixed layer and upper thermocline waters

Corresponding author address: Michael R. Bueti, Graduate School of Oceanography, University of Rhode Island, 215 South Ferry Rd., Narragansett, RI 02882.

E-mail: mbueti@my.uri.edu
(Price 1981), and anomalous surface buoyancy fluxes and upwelling induced by the strong wind stress curl.

SST returns to its climatological value within $30-40$ days regardless of storm intensity (Dare and McBride 2011), with local restoration due to anomalous heat flux associated with SST cooling (Price et al. 2008). Furthermore, restoration of the shallow cooling takes place over similar time scales, although full climatological mixed layer (CML) restoration takes several months (Park et al. 2011; Price et al. 2008). However, the subsurface warm anomalies decay over much longer time scales (Pasquero and Emanuel 2008) since they are not subject to the same restoration processes as the mixed layer cold anomaly. Emanuel (2001) estimated that the restoration of an idealized cold wake could result in the introduction of up to $5 \times 10^{21} \mathrm{~J}$ of anomalous ocean heat uptake (OHU). Extending this analysis to an idealized modeling study he hypothesized that a full year of TC 
activity could produce an annual mean OHU rate of $1.4 \pm 0.7 \mathrm{PW}$.

Studies since Emanuel (2001) have attempted to refine the magnitude of TC-induced ocean heating based on global observations from remote sensing instruments. Sriver and Huber (2007) used satellite SST and ocean reanalysis to derive a mean annual TC-induced $\mathrm{OHU}$ rate of $0.26 \mathrm{PW}$, later revised to a peak value of $0.6 \mathrm{PW}$ and accompanying $60 \%$ increase in ocean heat transport (OHT) based on refined estimates of mixed layer (ML) deepening (Sriver et al. 2008). Jansen et al. (2010) utilized SST and sea surface height (SSH) satellite observations, and ML depth and stratification from ocean reanalysis, to estimate a mean annual seasonal thermocline heat deposition rate of $0.58 \mathrm{PW}$, which may produce a comparable $\mathrm{OHU}$

Jansen et al. (2010) hypothesized that the magnitude of persistent TC heat pumping is systematically overestimated on interannual time scales, with upperthermocline warm anomalies entrained into the winter ML and reventilated to the atmosphere. Accounting for this heat release results in a mean annual OHU rate of $0.15 \mathrm{PW}$, a $75 \%$ reduction of their previous estimate. Shoaling of upper thermocline warm anomalies by baroclinic ML instabilities enhances this reventilation, a process unaccounted for in most observational estimates (Jansen et al. 2010; Boccaletti et al. 2007). Pasquero and Emanuel (2008) found that equatorial upwelling also releases TC OHU to the atmosphere. Using gridded SSH measured from satellites, Mei et al. (2013) derived a global annual $\mathrm{OHU}$ of $1.01 \pm 0.46 \times 10^{22} \mathrm{~J}$ and a mean annual rate of $0.32 \pm 0.15 \mathrm{PW}$ from the thermal expansion needed to account for TC-induced SSH anomalies.

Argo float data have recently been used to directly quantify TC OHU. Park et al. (2011) used pre- and poststorm float pairs to estimate TC-induced OHU, finding that storms of category 3 or less $(\sim 85 \%$ of annual TCs) produce no detectable subsurface warming, with the remaining storms producing an OHU rate of $\sim 0.19 \pm$ $0.03 \mathrm{PW}$. The spatial and temporal sparseness of in situ observations in relation to storm tracks, effects of Ekman pumping, inertia-gravity waves, and other background variability make the accurate quantification of TCinduced $\mathrm{OHU}$ from these observations quite difficult.

Numerical modeling studies with varying levels of dynamic and thermodynamic idealization have also been used to study the magnitude and mechanisms of TC OHU. Pasquero and Emanuel (2008) used a $4^{\circ}$ horizontal resolution ocean general circulation model (OGCM) with specified mixing to $75 \mathrm{~m}$, equivalent to a $25-\mathrm{m}$ deepening of the ML, resulting in $1.1 \times 10^{22} \mathrm{~J}$ of OHU over 12 months of model integration, from which we estimate a mean annual rate of $0.35 \mathrm{PW}$. Approximately
$50 \%$ of this heating persisted through the winter, while anomalies from mixing down to $155 \mathrm{~m}$ had $\sim 80 \%$ retention. Sriver and Huber (2010) specified realistic TC wind forcing derived from Quick Scatterometer (QuikScat) data in a $3.6^{\circ}$ zonal by $1.5^{\circ}$ meridional resolution OGCM. By doubling and tripling the TC winds, mean $\mathrm{OHU}$ rates varied from $0.1 \mathrm{PW}$ to 0.3 and $0.8 \mathrm{PW}$ respectively, during 500 years of model integration. Anomalous heat transport was predominantly into the tropics, warming the upper $300 \mathrm{~m}$ of the tropical Pacific, with much of the heat deposited in the Equatorial Undercurrent (EUC).

Enhanced diffusivity of $\kappa \sim 1 \mathrm{~cm}^{2} \mathrm{~s}^{-1}$ has been used as a proxy for TC wind forcing. Manucharyan et al. (2011) used this method in the upper $200 \mathrm{~m}$ of the ocean between $8^{\circ}$ and $40^{\circ}$ latitude in a $1.25^{\circ}$ zonal and $0.25^{\circ}-1^{\circ}$ meridional resolution OGCM. Enhanced mixing was applied uniformly in time, seasonally, and as discrete multiday events repeated over 200 years of model integration, with the resulting $\mathrm{OHU}$ producing an average $\sim 0.2 \mathrm{PW}$ of poleward and equatorward OHT over the last 25 years of simulation. Forcing was found to be most effective when applied during the local summer, demonstrating sensitivity to temporal variability in TC activity. Jansen and Ferrari (2009) demonstrated a sensitivity to the meridional distribution of $\mathrm{TC}$ forcing in a $2.8^{\circ}$ resolution OGCM by introducing an enhanced diffusivity uniformly between $31^{\circ} \mathrm{N} / \mathrm{S}$, with gaps imposed between $11.2^{\circ} \mathrm{N} / \mathrm{S}$ and $5.6^{\circ} \mathrm{N} / \mathrm{S}$. Increases in poleward OHT reached values of $0.24 \mathrm{PW}$ with no equatorial gap, which decreased to $\sim 0.175$ and $\sim 0.15 \mathrm{PW}$ with increasing gap size during their 100-yr analysis timeframe. These gaps also allow for enhanced OHT into the tropics of $\sim 0.15$ and $\sim 0.25 \mathrm{PW}$, respectively.

Scoccimarro et al. (2011) used a coupled oceanatmosphere general circulation model with a $2^{\circ}$ resolution ocean, finding a $35 \%$ increase in equatorward $\mathrm{OHT}$ between $0^{\circ}$ and $18^{\circ} \mathrm{N}(\sim 0.5 \mathrm{PW})$, a $5 \%$ increase in poleward OHT between $18^{\circ}$ and $40^{\circ} \mathrm{N}(\sim 0.1 \mathrm{PW})$ attributed to the presence of TCs during their 120 -yr experiment. While their $3 / 4^{\circ}$ resolution atmosphere reproduced the climatology of TC distribution and movement, it underestimated the annual frequency by $\sim 15 \%$, with a bias toward weaker storms. Jullien et al. (2012) conducted a finer-resolution $\left(1 / 3^{\circ}\right)$ regional study in the South Pacific, with surface forcing from global Weather Research and Forecasting (WRF) model output with and without TCs. They derived a regional OHU rate of $\sim 0.015 \mathrm{PW}$ during the southern TC season, with an attenuation of $\sim 0.009 \mathrm{PW}$ over the winter. This region is subject to $10 \%-15 \%$ of global TC activity, and of those the WRF forcing contains fewer major TCs than observed. 
Recently, Vincent et al. (2013) used a $1 / 2^{\circ}$ OGCM initialized from World Ocean Atlas climatology and forced with winds from version 2.0 of the Coordinated Ocean-Ice Reference Experiments (CORE-II) and synthetic vortices based on the International Best Track Archive for Climate Stewardship (IBTrACS) record and Willoughby et al. (2006) wind profile formulation to explore the impact of TCs on the mean ocean state. They found broad cooling in the mixed layer, with underlying warming and cooling in the upper thermocline due to mixing and upwelling/downwelling, and offsetting warming and cooling deeper in the water column due only to upwelling/downwelling. They attempted to account for cooling from enhanced fluxes during TC passage offsetting the impact of mixing-induced $\mathrm{OHU}$, as well as fall/winter release of heat anomalies to the atmosphere via surface heat fluxes. They quantified the average $3 \mathrm{D}$ response in various regions, finding subsurface warming in the subtropical northwest Pacific down to nearly $200 \mathrm{~m}$ underlying cooling to $\sim 40 \mathrm{~m}$. They found that $\sim 1 / 4$ of TC heating is transported out of its region of generation, with $\sim 40 \%$ released locally during winter ML deepening and $\sim 1 / 3$ compensated by loss of heat to the atmosphere during TC passage. Meridional OHT was derived from a surface flux-based overturning, with all anomalous heat moving on average from latitudes of net input to those of heat release, displaying a transport from the subtropics poleward to the midlatitudes, and equatorward to the deep tropics. This assumed a quasi-steady-state response interannually, and stressed the importance of dynamical effects over mixing in many cases for heat transport.

We expand on previous studies of this topic using a global ocean-ice general circulation model of finer resolution than those used in previous studies, with realistic TC surface boundary conditions. In this way, we hope to better understand the rate and magnitude of TCinduced $\mathrm{OHU}$ over intraseasonal and interseasonal time scales, both globally and in the individual ocean basins. Specifically, we will enumerate and contextualize this heat uptake for a single year, explore its regional climate significance, and detail likely pathways and time scales that dictate the export of heat from the dominant TC forcing regions.

\section{Methods}

\section{a. The ocean model}

We use the Geophysical Fluid Dynamics Laboratory's (GFDL's) Modular Ocean Model (MOM), version 4 (Griffies 2009). MOM is a hydrostatic primitive equation ocean model configured using a Boussinesq approximation with a free surface algorithm and coupled to the Sea Ice Simulator (SIS) ice model to handle processes in the high latitudes. We utilize an ocean-ice configuration with its resolution taken from the GFDL Climate Model version 2.5 (CM2.5) documented in Delworth et al. (2012). The horizontal resolution varies from $28 \mathrm{~km}$ at the equator to $8-11 \mathrm{~km}$ at high latitudes. The model has 50 vertical levels, 23 of which are in the upper $500 \mathrm{~m}$ of the ocean.

The upper ocean mixing and restratification is of particular importance in evaluating the ocean's response to TCs. Vertical mixing of tracers and momentum is handled by the $K$ profile parameterization (KPP) boundary layer scheme (Large et al. 1994), which computes enhanced mixing within a boundary layer depth determined according to a bulk Richardson number. Mixing of tracers also arises in regions of negative surface buoyancy fluxes from a nonlocal transport term proportional to surface boundary heat and salt fluxes. Beneath the boundary layer, tracer mixing arises due to parameterized shear instability, tide-induced mixing, double diffusion, and convection due to gravitational instabilities. The parameterized mixing is thus highly variable in both space and time, producing mixing that is strongly dependent on the applied surface forcing. MOM parameterizes the effect of submesoscale mixed layer eddies according to Fox-Kemper et al. (2011), with these eddies enhancing the ventilation of TC warm anomalies (Jansen et al. 2010).

\section{b. Air-sea fluxes and TC forcing}

The ocean model is forced with air-sea boundary conditions as in the CORE-II experiments described by Griffies et al. (2009). The prescribed atmospheric state is from the corrected interannual forcing product (Large and Yeager 2009) with a $1^{\circ}$ resolution, providing sea level pressure, air temperature, specific humidity, and zonal and meridional winds at $10 \mathrm{~m}$ every six hours; daily average values for incoming shortwave and longwave radiation; and monthly averages of liquid and frozen precipitation rates. The CORE-II winds are relatively coarse, so that TC winds are poorly resolved, if present at all. As an example, the strong winds in the compact TC eyewall region of category 4 Hurricane Frances (here on 1 September 2004 north of Hispaniola), critical for producing ocean mixing, are entirely absent (Fig. 1a).

In this study we introduce two changes to the CORE-II boundary conditions. First, the parameterization of the drag coefficient, $C_{D}$, is modified for strong winds. The linear relationship between wind speed and $C_{D}$ (Large and Yeager 2004) used in CORE-II greatly overestimates the wind stress for high wind speeds, particularly those present in tropical cyclones (Powell et al. 2003; 
(a)

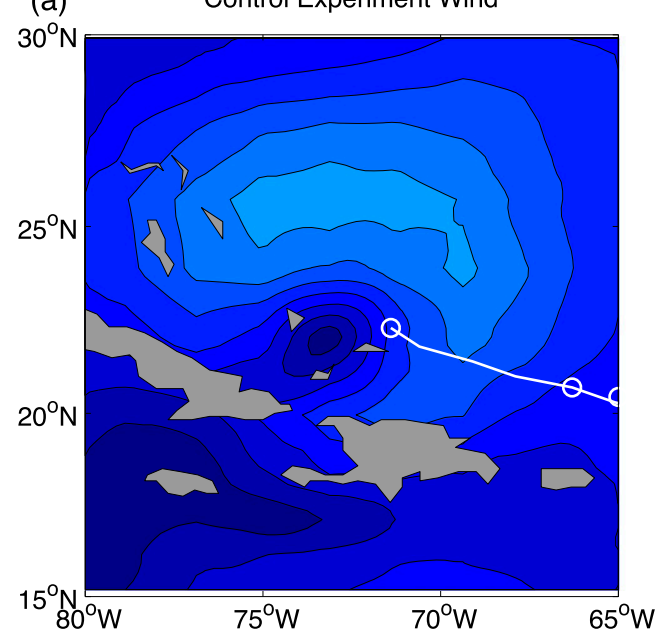

(b)

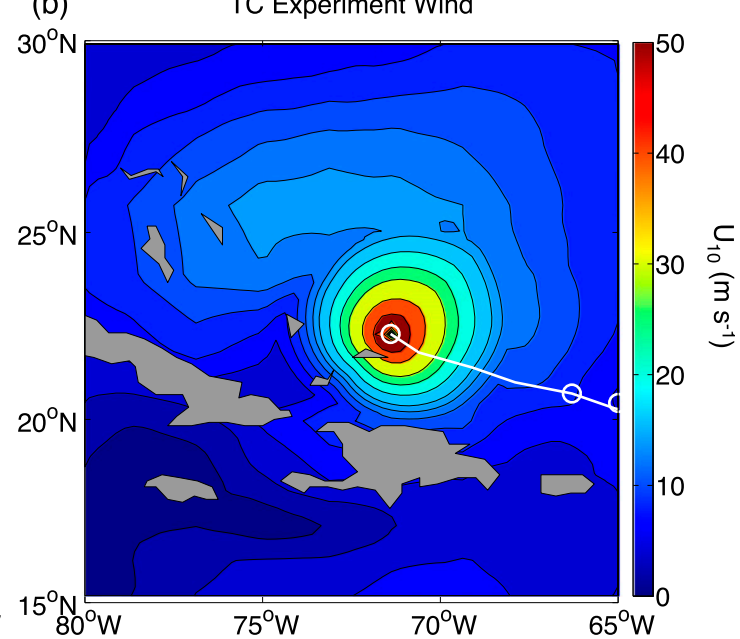

FIG. 1. 10-m wind speed magnitude during Hurricane Frances (a) from the control experiment and (b) with the embedded TC.

Moon et al. 2007). The high $C_{D}$ values result in unrealistically intense vertical mixing (Sanford et al. 2007). For wind speeds greater than $12.5 \mathrm{~m} \mathrm{~s}^{-1}$, we replace the Large and Yeager (2004) parameterization with the formulation of Moon et al. (2007), empirically derived from coupled wave-wind model simulations in hurricanes. The hybrid drag coefficient increases more slowly than in Large and Yeager (2004) and levels off for wind speeds greater than $40 \mathrm{~m} \mathrm{~s}^{-1}$.

Second, we modify the CORE-II winds by introducing synthetic TCs based on the National Hurricane Center (NHC) and Joint Typhoon Warning Center (JTWC) Tropical Cyclone Vitals Database (TCVitals). This database contains cyclone location, intensity, and structure information, generated in real time by forecasters (Tables 1 and 2). TCVitals data are used to initialize cyclones in operational forecasting models. We use TCVitals data because they contain parameters such as radius of maximum wind, radius of last closed isobar, and the radii at which winds reach values of 18 and $26 \mathrm{~m} \mathrm{~s}^{-1}$ in the northeast, southeast, southwest, and northwest quadrants of the storm (extended structure data), which are not consistently available for all basins from the IBTrACS or NHC's North Atlantic hurricane database (HURDAT2). While there are statistical biases in storm intensity $\left(\sim 0.25-1 \mathrm{~m} \mathrm{~s}^{-1}\right)$ and location $(0-5 \mathrm{~km})$ compared to the best-track database (Trahan and Sparling 2012), these errors should have negligible impact on the results of this study.

Air-sea heat fluxes are calculated from bulk formulas as described in Griffies et al. (2009). No explicit SST restoration is applied. Surface heat fluxes are allowed to freely evolve under the specified atmospheric state and respond to both the enhanced TC winds and cooled SSTs in the storm cold wakes. The air temperature and humidity are unperturbed from their CORE-II values

TABLE 1. Sample TCVitals for Hurricane Frances position, central pressure, environmental pressure, maximum wind speed, radius of last closed isobar, radius of maximum wind, and radii with wind speed of 18 and $26 \mathrm{~m} \mathrm{~s}^{-1}$ in all quadrants [northeast (NE), southeast (SE), southwest (SW), and northwest (NW)].

\begin{tabular}{|c|c|c|c|c|c|c|c|c|c|c|c|c|c|c|c|}
\hline \multirow{3}{*}{$\begin{array}{c}\text { Date and time } \\
\text { (all dates are in 2004) }\end{array}$} & \multicolumn{2}{|c|}{ Position } & \multirow{2}{*}{\multicolumn{2}{|c|}{ Pressure (mb) }} & \multirow{3}{*}{$\begin{array}{c}\text { Max wind } \\
\text { speed }\left(\mathrm{m} \mathrm{s}^{-1}\right)\end{array}$} & \multicolumn{10}{|c|}{ Radius (km) } \\
\hline & \multirow{2}{*}{$\begin{array}{l}\text { Lat } \\
\left({ }^{\circ} \mathrm{N}\right)\end{array}$} & \multirow{2}{*}{$\begin{array}{l}\text { Lon } \\
\left({ }^{\circ} \mathrm{W}\right)\end{array}$} & & & & \multirow{2}{*}{$\begin{array}{l}\text { Last closed } \\
\text { isobar }\end{array}$} & \multirow{2}{*}{$\begin{array}{l}\text { Max } \\
\text { wind }\end{array}$} & \multicolumn{4}{|c|}{$18 \mathrm{~m} \mathrm{~s}^{-1}$} & \multicolumn{4}{|c|}{$26 \mathrm{~m} \mathrm{~s}^{-1}$} \\
\hline & & & Central & $\overline{\text { Env }}$ & & & & $\mathrm{NE}$ & $\mathrm{SE}$ & SW & NW & $\mathrm{NE}$ & $\mathrm{SE}$ & SW & NW \\
\hline 0000 UTC 31 August & 19.6 & 60.7 & 945 & 1012 & 57 & 37 & 28 & 278 & 241 & 185 & 278 & 167 & 148 & 130 & 167 \\
\hline 0600 UTC 31 August & 19.8 & 62.1 & 951 & 1012 & 5 & & 3 & 278 & 241 & 185 & 278 & 167 & 148 & 130 & 167 \\
\hline 1200 UTC 31 August & 19.9 & 63.3 & 950 & 1012 & 59 & 371 & 37 & 278 & 241 & 185 & 278 & 167 & 167 & 130 & 167 \\
\hline 1800 UTC 31 August & 20.3 & 65.1 & 942 & 1012 & 62 & 371 & 37 & 278 & 241 & 185 & 278 & 185 & 185 & 139 & 185 \\
\hline 0000 UTC 1 September & 20.7 & 66.3 & 939 & 1012 & 62 & 371 & 28 & 278 & 241 & 185 & 278 & 185 & 185 & 139 & 185 \\
\hline 0600 UTC 1 September & 21.0 & 67.9 & 939 & 1012 & 62 & 371 & 28 & 297 & 241 & 185 & 278 & 222 & 185 & 139 & 185 \\
\hline 1200 UTC 1 September & 21.4 & 69.1 & 937 & 1012 & 62 & 371 & 28 & 297 & 241 & 185 & 278 & 222 & 185 & 139 & 185 \\
\hline 1800 UTC 1 September & 21.8 & 70.6 & 941 & 1012 & 62 & 371 & 28 & 297 & 241 & 148 & 278 & 222 & 139 & 111 & 139 \\
\hline
\end{tabular}


TABLE 2. Sample TCVitals for Typhoon Songda position, central pressure, environmental pressure, maximum wind speed, radius of last closed isobar, radius of maximum wind, radii with wind speed of $18 \mathrm{~m} \mathrm{~s}^{-1}$ in all quadrants (NE, SE, SW, and NW); $26 \mathrm{~m} \mathrm{~s}{ }^{-1}$ wind radii are not present in JTWC records.

\begin{tabular}{|c|c|c|c|c|c|c|c|c|c|c|c|c|c|c|c|}
\hline \multirow{3}{*}{$\begin{array}{c}\text { Date and time } \\
\text { (all dates are in 2004) }\end{array}$} & \multicolumn{2}{|c|}{ Position } & \multirow{2}{*}{\multicolumn{2}{|c|}{ Pressure (mb) }} & \multirow{3}{*}{$\begin{array}{c}\text { Max wind } \\
\text { speed }\left(\mathrm{m} \mathrm{s}^{-1}\right)\end{array}$} & \multicolumn{10}{|c|}{ Radius $(\mathrm{km})$} \\
\hline & \multirow{2}{*}{$\begin{array}{l}\text { Lat } \\
\left({ }^{\circ} \mathrm{N}\right)\end{array}$} & \multirow{2}{*}{$\begin{array}{l}\text { Lon } \\
\left({ }^{\circ} \mathrm{E}\right)\end{array}$} & & & & \multirow{2}{*}{$\begin{array}{c}\text { Last } \\
\text { closed isobar }\end{array}$} & \multirow{2}{*}{$\begin{array}{l}\text { Max } \\
\text { wind }\end{array}$} & \multicolumn{4}{|c|}{$18 \mathrm{~m} \mathrm{~s}^{-1}$} & \multicolumn{4}{|c|}{$26 \mathrm{~ms}^{-1}$} \\
\hline & & & Central & Env & & & & $\mathrm{NE}$ & SE & SW & NW & $\mathrm{NE}$ & SE & SW & NW \\
\hline 0000 UTC 1 September & 18.4 & 146.3 & 916 & 1000 & 64 & 370 & 19 & 278 & 241 & 0333 & 0278 & - & - & - & - \\
\hline 0600 UTC 1 September & 19.6 & 145.4 & 916 & 1001 & 64 & 370 & 28 & 222 & 222 & 0222 & 0222 & - & - & - & - \\
\hline 1200 UTC 1 September & 20.2 & 143.5 & 916 & 1001 & 6 & 37 & 28 & 278 & 278 & 0278 & 0278 & - & - & - & - \\
\hline 1800 UTC 1 September & 20.8 & 142.3 & 916 & 1001 & 64 & 370 & 28 & 278 & 278 & 0278 & 0278 & - & - & - & - \\
\hline 0000 UTC 2 September & 21.1 & 141.1 & 922 & 1001 & 62 & 370 & 28 & 278 & 278 & 0278 & 0278 & - & - & - & - \\
\hline 0600 UTC 2 September & 21.7 & 139.9 & 933 & 1001 & 57 & 370 & 19 & 148 & 278 & 0278 & 0148 & - & - & - & - \\
\hline 1200 UTC 2 September & 21.9 & 138.4 & 938 & 1001 & 54 & 370 & 19 & 204 & 278 & 0278 & 0204 & - & - & - & - \\
\hline 1800 UTC 2 September & 21.9 & 137.4 & 933 & 1001 & 57 & 370 & 19 & 204 & 278 & 0278 & 0204 & - & - & - & - \\
\hline
\end{tabular}

and do not respond to the ocean state, with implications for the character of these fluxes. Specifically, the elevation of latent and sensible heat fluxes out of the ocean in response to high TC wind speeds is underestimated in our simulations. Likewise, suppression of the latent heat flux out of the ocean and rate of the resulting upper ocean warming in the TCs cold wake may be somewhat overestimated.

Synthetic TC wind speeds are generated for each storm in the TCVitals as is done for operational hurricane forecasting (Bender et al. 2007). The cyclone wind field is projected onto the ocean model grid, and at any location where the CORE-II wind speed is lower than the TC wind speed it is replaced by the latter (Fig. 1b). For cases when the extended structure data are unavailable, the axisymmetric wind profile of Holland (1980) is used. The Holland (1980) axisymmetric profile comprises only $\sim 20 \%$ of storm hours, typically during cyclogenesis and storm dissipation. Further details of the wind formulation and the blending method are described in the appendix.

The 2004/05 global TC season is simulated from the start of the North Atlantic hurricane season (1 June) and integrated for one full calendar year. There were 92 TC events during these 12 months (Fig. 2), with the greatest number in the west Pacific (WestPac) (30), a significant number in the North Atlantic (16), east Pacific (EastPac) (17), and Southern Hemisphere (18), and a few in the North Indian Ocean (3). The boundaries and oceanic surface areas of these basins are defined in Table 3.

\section{c. Experimental procedure}

The model is run from 1 June 2004 through 31 May 2005 in two forcing configurations. The first has surface forcing based on the CORE-II atmospheric state, and we will refer to this experiment as the control experiment (Fig. 1a). The other configuration has the CORE-II surface wind augmented by embedding the synthetic TCs, and will be referred to as the TC experiment (Fig. 1b). An "anomaly" is defined as the difference between the oceans in the TC and control experiments, thus yielding the net thermal and dynamical effect of TC activity.

Ocean initial conditions are derived from GFDL's Ocean Data Assimilation Experiment (ODAE) product, described by Zhang et al. (2007). This product provides the average monthly temperature and salinity fields at $1^{\circ}$ grid spacing. MOM is started on 1 December 2003 from the ODAE December 2003 field interpolated onto the ocean model grid, with air-sea fluxes computed based on the CORE-II atmospheric state. The model is run for 6 months. At this point, the ocean has reached a mechanical quasi-steady state with the ocean's globally integrated total kinetic energy being $~ 3500$ PJ.

\section{d. Seasonal behavior}

To evaluate the seasonal behavior of the ocean model and set a baseline against which to compare TC heating values, the seasonal component of the upper ocean heat content $(\mathrm{OHC})$ is calculated. $\mathrm{OHC}$ is defined as

$$
\begin{gathered}
\operatorname{OHC}(t)=c_{p} \rho_{o} \int_{-729 \mathrm{~m}}^{0 \mathrm{~m}} d z \int_{x_{w}}^{x_{e}} d x \int_{y_{s}}^{y_{n}} d y \Delta T_{729 \mathrm{~m}}, \\
\Delta T_{729 \mathrm{~m}}=T(x, y, z, t)-T(x, y, z=-729 \mathrm{~m}, t),
\end{gathered}
$$

where $\left[x_{w}, x_{e} ; y_{s}, y_{n}\right]$ are the [zonal; meridional] domain boundaries. The 729-m depth level is selected as it is the closest model level to the 700-m depth used by in situ analyses, such as Levitus et al. (2012). The seasonal OHC variability is defined as

$$
\Delta \mathrm{OHC}_{\text {season }}(t)=\mathrm{OHC}(t)-\overline{\mathrm{OHC}(t)},
$$

where the overbar denotes time averaging from 1 June to 31 May. A 30-day low-pass filter is applied in order to 


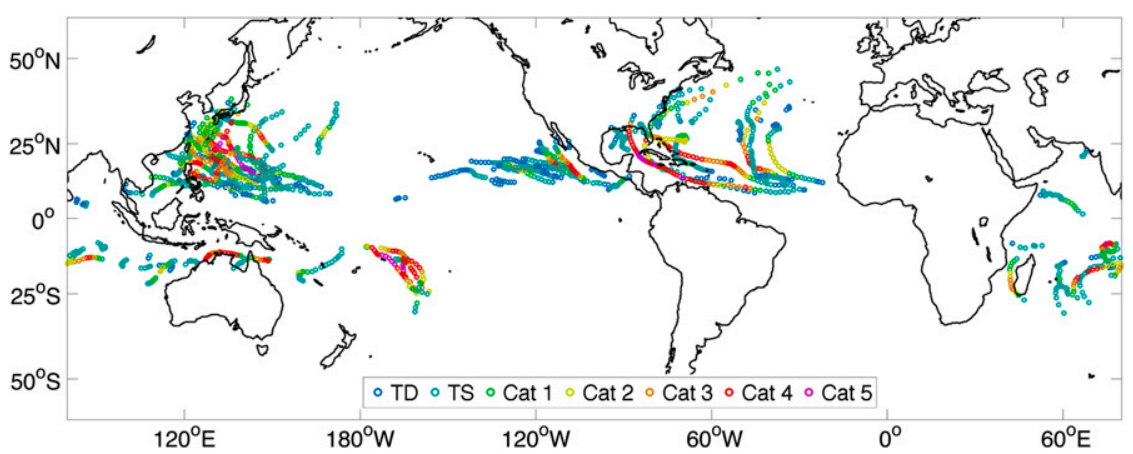

FIG. 2. Global TC tracks from 1 Jun 2004 through 31 May 2005, colored by storm intensity.

isolate the seasonal behavior from higher-frequency variability.

The seasonal OHC amplitude in MOM is compared to that found by applying Eq. (2) to an independent data source, the Navy Coupled Ocean Data Assimilation (NCODA) product (Cummings 2005). As NCODA data at a consistent horizontal resolution are not available until the 2007 calendar year, $\Delta \mathrm{OHC}_{\text {season }}$ in $\mathrm{MOM}$ is calculated for both 1 June 2004-31 May 2005 and 1 June 2007-31 May 2008, presented in Fig. 3. The value of $\Delta \mathrm{OHC}_{\text {season }}$ is consistent between model run years, with little difference in phase and amplitude. The seasonal $\mathrm{OHC}$ in $\mathrm{MOM}$ is on average $\sim 8 \%$ smaller than in NCODA (although at times this discrepancy is closer to $\sim 18 \%$ ), but otherwise in good agreement. This comparison gives confidence that MOM is capturing the seasonal behavior of $\mathrm{OHC}$ reasonably well. The maximum global excursion of $\Delta \mathrm{OHC}_{\text {season }}$ (calculated as the sum of the Northern and Southern Hemisphere extrema), as well as those for the individual ocean basins, is presented in Table 4. A cross-comparison of ML depths between MOM and NCODA was conducted as well. While not shown, the temporal and spatial structure of the modeled ML was generally consistent with that derived from NCODA data.

\section{Results}

\section{a. Test cases}

Two TC cases are considered to test the model response and explore the physical processes involved in simulating the ocean response to TC passage. In this way the suitability of our analysis is established. We select 2004's Hurricane Frances (Table 1), a category 4 hurricane that took place from 25 August to 7 September 2004 in the North Atlantic, and Typhoon Songda (Table 2), a category 4 typhoon that took place from 27 August to 7 September 2004 in the west Pacific. The Hurricane Frances case is selected due to the availability of observational data from the Coupled Boundary Layers and Air-Sea Transfer (CBLAST) field experiment (Black et al. 2007; D'Asaro et al. 2007). Typhoon Songda is selected for comparison of the ocean response to a TC with similar intensity, duration, and track length in the west Pacific.

To investigate the restoration time scale of TC-induced anomalies, model integration is carried out through 31 December 2004 ( $\sim 2$ weeks of storm passage and just over 4 months of ocean recovery). SST and $\Delta$ SST following passage of Hurricane Frances and Typhoon Songda are shown in Fig. 4, with both TCs producing strong cold wakes by 5 September. Figure 5 focuses on the cold wake of Hurricane Frances on 1 September, with domain boundaries selected to approximate those in Fig. 1 from D'Asaro et al. (2007). Note that on 1 September the modeled background SST, and thus the cold wake SST, displays a $\sim 0.5^{\circ} \mathrm{C}$ low bias in this region as compared to the observations, and so a corresponding shift has been made in the color range of Fig. 5 relative to Fig. 1 in D'Asaro et al. (2007). The model exhibits a cooling of $2.5^{\circ} \mathrm{C}$ (Fig. $5 b$ ) comparable to the $2.2^{\circ} \mathrm{C}$ maximum SST anomaly found in the same region by D'Asaro et al. (2007). Hurricane heat content integrated

TABLE 3. Geographical boundaries and ocean surface area of TC ocean basins.

\begin{tabular}{llcc}
\hline \hline \multicolumn{1}{c}{ Basin } & Lon. bounds & Lat. bounds & $\begin{array}{c}\text { Area } \\
\left(\text { million } \mathrm{km}^{2}\right)\end{array}$ \\
\hline Globe & $180^{\circ} \mathrm{W}-180^{\circ} \mathrm{E}$ & $80^{\circ} \mathrm{S}-\mathrm{N}$ & 358.63 \\
West Pacific & $98^{\circ}-180^{\circ} \mathrm{E}$ & $0^{\circ}-90^{\circ} \mathrm{N}$ & 39.916 \\
East Pacific & $180^{\circ}-100^{\circ} \mathrm{W}^{*}$ & $0^{\circ}-90^{\circ} \mathrm{N}$ & 47.719 \\
North Atlantic & $100^{\circ} \mathrm{W}^{*}-20^{\circ} \mathrm{E}$ & $0^{\circ}-90^{\circ} \mathrm{N}$ & 49.52 \\
North Indian & $20^{\circ}-98^{\circ} \mathrm{E}$ & $0^{\circ}-90^{\circ} \mathrm{N}$ & 15.115 \\
$\quad$ & & \\
$\quad$ Ocean & & & \\
Southern & $180^{\circ} \mathrm{W}-180^{\circ} \mathrm{E}-0^{\circ}$ & 206.32 \\
$\quad$ Hemisphere & & & \\
\hline
\end{tabular}

* South of $17^{\circ} \mathrm{N}$ the boundary between the east Pacific and North Atlantic is defined by the Central American isthmus and South American continent. 


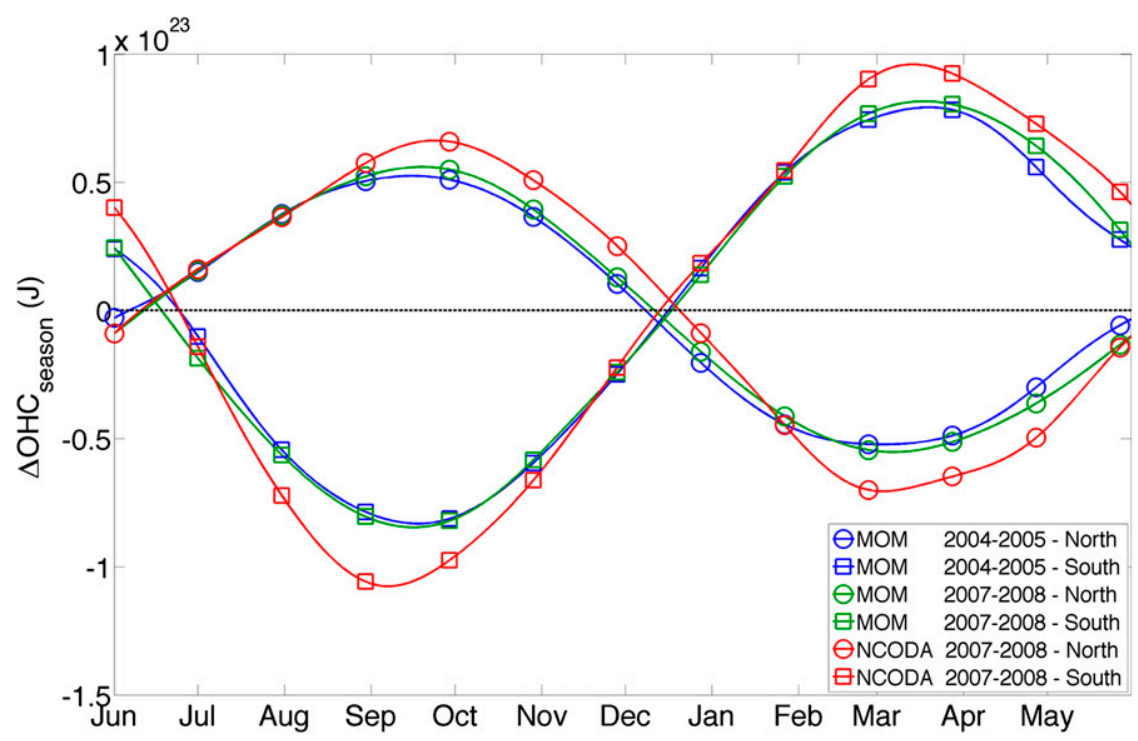

FIG. 3. Northern and Southern Hemisphere seasonal variability $\left(\Delta \mathrm{OHC}_{\text {season }}\right)$ for $1 \mathrm{Jun}$ 2004-31 May 2005 in MOM, 1 Jun 2007-31 May 2007 in MOM, and 1 Jun 2007-31 May 2007 in NCODA.

to the $26^{\circ} \mathrm{C}$ isotherm, defined in D'Asaro et al. (2007), is reduced by $\sim 100 \mathrm{~m}^{\circ} \mathrm{C}^{-1}$ (Fig. $5 \mathrm{~d}$ ), comparable to the $\sim 125 \mathrm{~m}^{\circ} \mathrm{C}^{-1}$ from D'Asaro et al. (2007). The cold wake of Frances is consistent in spatial structure with CBLAST observations.

Typhoon Songda produces a stronger simulated cold wake (Figs. $4 \mathrm{c}, \mathrm{d}$ ) with maximum cooling $\sim 5.5^{\circ} \mathrm{C}$. Songda passes over a more strongly stratified ocean (Fig. 9b), allowing for a more intense modeled cold wake (Vincent et al. 2012b), with its slower translation speed during the period of maximum cooling $\left(\sim 5 \mathrm{~m} \mathrm{~s}^{-1}\right)$ compared to that of Frances $\left(\sim 6 \mathrm{~m} \mathrm{~s}^{-1}\right)$ reinforcing the effect (Yablonsky and Ginis 2009; Mei and Pasquero 2013). The modeled cold wake of Songda is consistent with remote sensing observations taken from Advanced Microwave Scanning Radiometer for Earth Observing System (AMSR-E) swath data (Fig. 6), with similar spatial structure and SSTs in the core of the wake as low as $22^{\circ} \mathrm{C}$ in both cases.

In Fig. 7, the recovery $e$-folding time $(\tau)$ of the sea surface temperature anomaly $(\Delta \mathrm{SST})$ is presented, with means and standard deviations of those times calculated within the shown $\Delta$ SST bins. Dare and McBride (2011) calculated the SST recovery time for cold wakes found in the daily $1 / 4^{\circ}$ resolution Reynolds et al. (2007) SST analysis product. The position and time of cold wakes was determined for each storm in the IBTrACS during the 1981-2008 period, showing that surface cold anomalies were restored with an $e$-folding time $\sim 8.5$ days. From the daily MOM output a local recovery $e$-folding time is calculated for every model grid point determined to be within the cold wake of either Hurricane Frances or Typhoon Songda. This recovery time is based on an exponential decay model $\Delta \mathrm{SST}=\Delta \mathrm{SST}_{o} e^{-\left(t-t_{o}\right) / \tau}$, where $\Delta \mathrm{SST}_{o}$ is the initial SST cooling and $t_{o}$ is the time of storm passage for that location. Figure 7 is produced from the results of this fit, with an average $e$-folding time of $\sim 8.75$ days, in good agreement with the findings of Dare and McBride (2011), and somewhat faster than the $\sim$ 11-day $e$-folding time derived by Mei and Pasquero (2013). As in the results of Dare and McBride (2011), recovery time shows no statistically significant dependence on the strength of initial cooling.

TC-induced subsurface anomalies are addressed next. Figure 8 illustrates the cross-track structure of the cold wake behind Typhoon Songda, with the cold anomaly in the upper $50 \mathrm{~m}$ centered $\sim 25 \mathrm{~km}$ to the right of the storm track, corresponding to upward mixing and upwelling of thermocline waters into the mixed layer. Cooling

TABLE 4. Maximum global and basin ocean heat uptake, compared to the local maximum of the $\Delta \mathrm{OHC}_{\text {season }}$ amplitude calculated to $729 \mathrm{~m}$ [Eq. (2)]. Timing of Maximum OHU are those found in Fig. 16.

\begin{tabular}{lccc}
\hline \multicolumn{1}{c}{ Basin } & $\begin{array}{c}\text { Max OHU } \\
\left(10^{21} \mathrm{~J}\right)\end{array}$ & $\begin{array}{c}\Delta \mathrm{OHC}_{\text {season }} \\
\left(10^{21} \mathrm{~J}\right)\end{array}$ & $\begin{array}{c}\mathrm{OHU} / \\
\Delta \mathrm{OHC}_{\text {season }}\end{array}$ \\
\hline Global & 4.10 & 135.7 & $3.0 \%$ \\
West Pacific & 1.52 & 16.9 & $9.0 \%$ \\
East Pacific & 1.72 & 17.2 & $10.0 \%$ \\
North Atlantic & 1.70 & 26.2 & $6.5 \%$ \\
North Indian Ocean & 0.31 & 7.3 & $4.2 \%$ \\
Southern Hemisphere & 2.50 & 83.2 & $3.0 \%$ \\
\hline
\end{tabular}



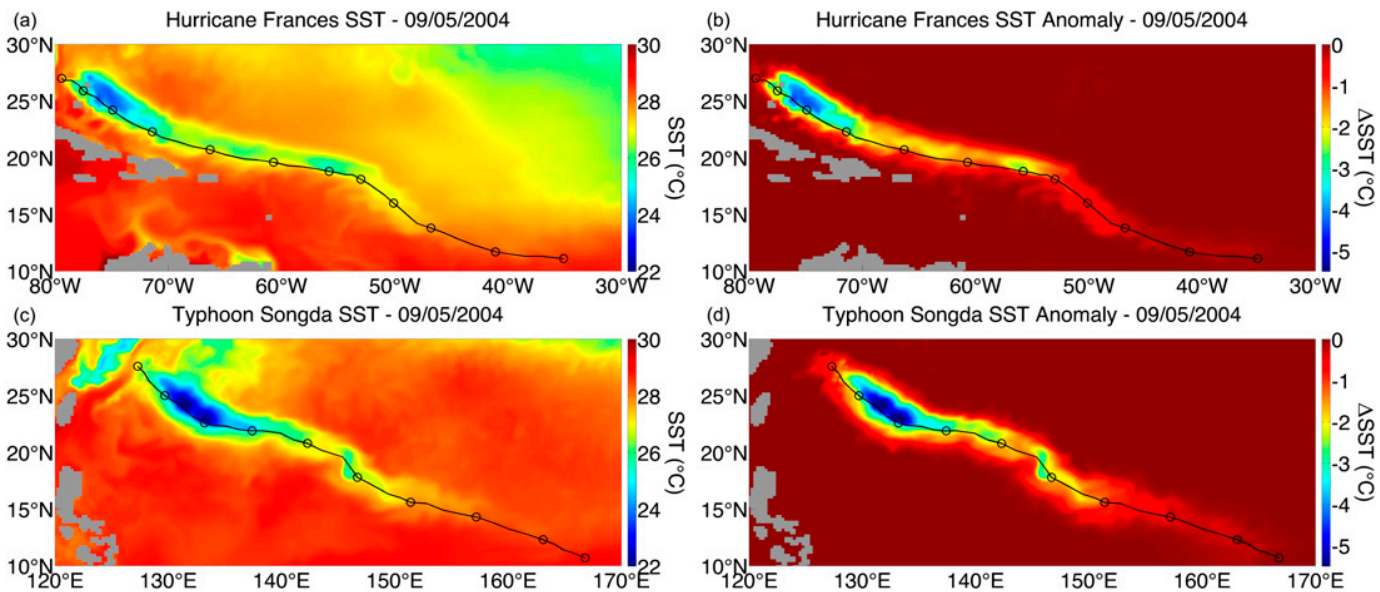

FIG. 4. Sea surface temperature and SST anomaly fields following passage of (a),(b) Hurricane Frances and (c),(d)

Typhoon Songda with daily track positions on 5 Sep 2004.

directly below the track exceeds 750-m depth, consistent with Ekman pumping induced by the strong TC wind stress curl, and is offset by downwelling centered around 500 -m depth and $\sim 150 \mathrm{~km}$ from the storm track. Warming due to downward mixing of ML waters into the thermocline is present between 50- and 100-m depth to the right and left of the storm track. Warming of $\sim 2.5^{\circ} \mathrm{C}$ extends to nearly $200 \mathrm{~m}$, at depths that have been attributed to nonlinearities in the superposition of mixing-induced warming and downwelling (Vincent et al. 2013).
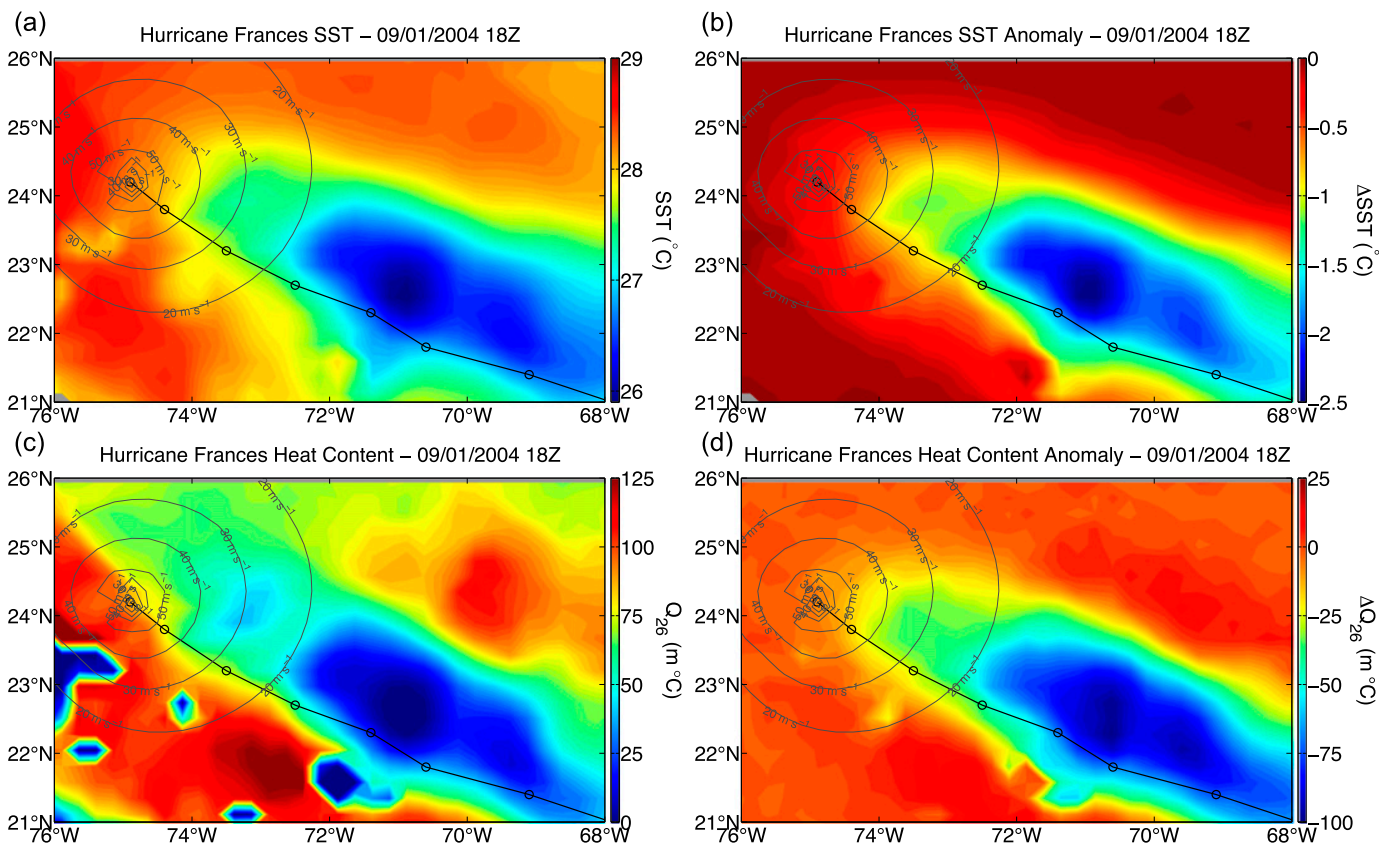

FIG. 5. (a) Sea surface temperature, (b) SST anomaly, (c) heat content, and (d) heat content anomaly integrated to the $26^{\circ} \mathrm{C}$ isotherm during passage of Hurricane Frances. Wind speed contours and track position are superimposed in gray and black, respectively. The domain limits were selected to approximate those of D'Asaro et al. (2007).
Mean temperature anomalies are calculated in the regions shown in Fig. 4, isolating the respective mixing effects of Frances and Songda while averaging out upwelling and downwelling effects. Immediately after storm passage there is surface cooling and subsurface warming (Fig. 9b). The depth and strength of mixing in the two storms is comparable, with Songda producing slightly more warming at depth, consistent with the stronger cold wake.

Ocean heat content anomaly $(\triangle \mathrm{OHC})$, ocean heat loss (OHL), and ocean heat uptake (OHU) are used to 

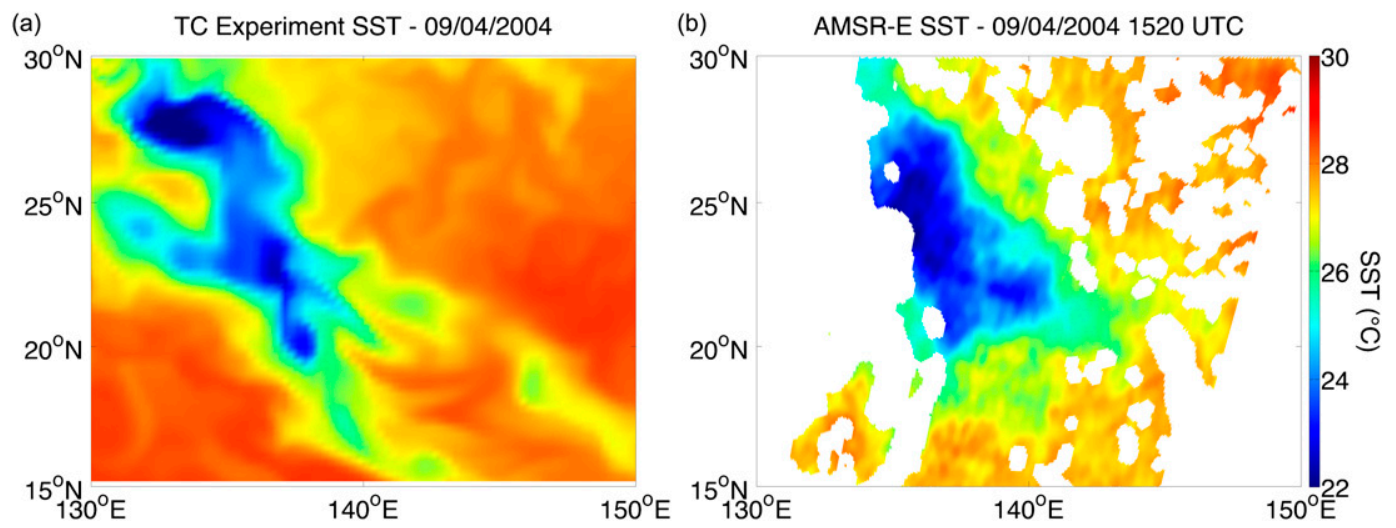

FIG. 6. Sea surface temperature from (a) MOM and (b) the AMSR-E level 2 satellite swath following passage of Typhoons Songda (27 Aug-7 Sep 2004) and Chaba (17-31 Aug 2004). The magnitude and extent of cooling are comparable in the model and satellite data.

quantify the bulk impact of TC heating and cooling. The $\mathrm{OHC}$ anomaly is defined as

$$
\Delta \mathrm{OHC}(t)=\mathrm{OHC}_{\mathrm{TC}}(t)-\mathrm{OHC}_{\mathrm{con}}(t),
$$

where $\mathrm{OHC}_{\mathrm{TC}}$ and $\mathrm{OHC}_{\text {con }}$ are the respective heat contents of the TC and control experiments calculated from Eq. (1a).

OHL and OHU decompose the heat content anomaly into shallow cooling and deep warming constituents:

$$
\operatorname{OHL}(t)=c_{p} \rho_{o} \int_{z_{1}}^{0} d z \int_{x_{w}}^{x_{e}} d x \int_{y_{s}}^{y_{n}} d y \Delta T(x, y, z, t)
$$

$\mathrm{OHU}(t)=c_{p} \rho_{o} \int_{z_{2}}^{z_{1}} d z \int_{x_{w}}^{x_{e}} d x \int_{y_{s}}^{y_{n}} d y \Delta T(x, y, z, t)$

where $\Delta T=T_{\mathrm{TC}}-T_{\text {con }}$. These integrals are first carried out horizontally, to obtain a heat anomaly profile with clear zero crossings (Fig. 9b). OHL is integrated from the surface through the cold anomaly to the first zero crossing $\left(z_{1}\right)$ and OHU from the first zero crossing until either the second zero crossing or, if one is not present, the warm anomaly has attenuated to $1 \%$ of its peak value $\left(z_{2}\right)$.

Time series of OHL and OHU are calculated through 31 December as OHL is attenuated to zero by mid to late December for both Frances and Songda (Fig. 10).

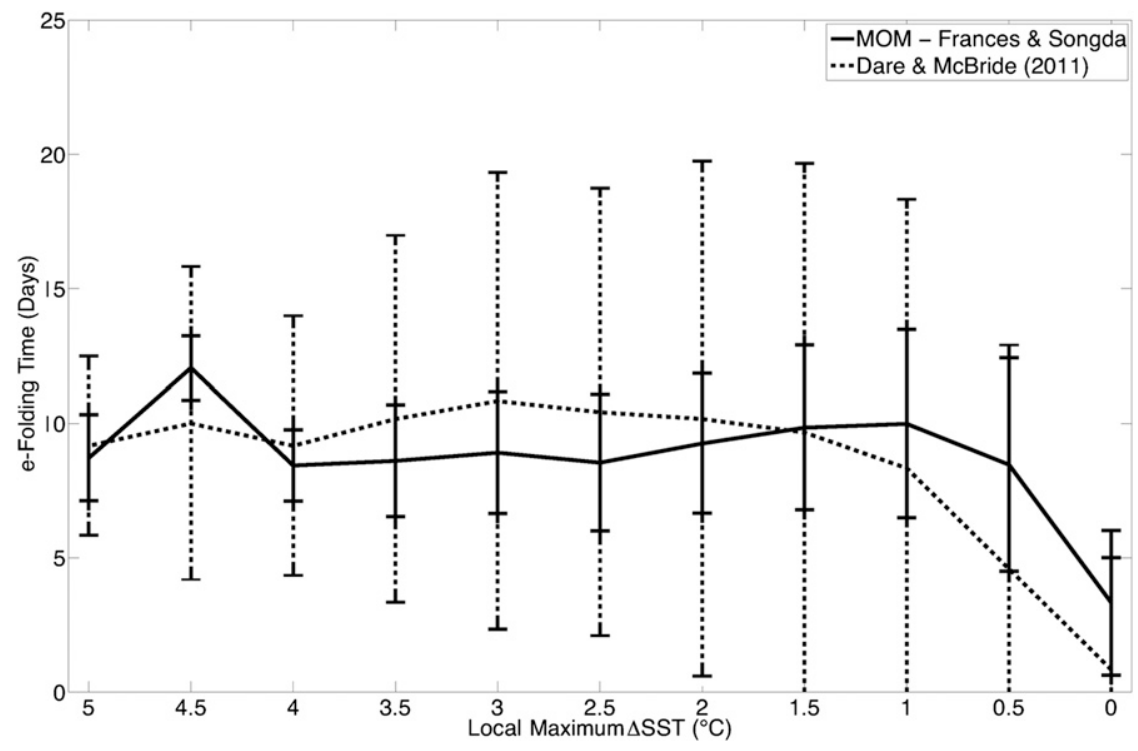

FIG. 7. SST recovery $e$-folding time following TC passage (solid), compared with results of Dare and McBride (2011) (dashed). Bars are the standard error on each $0.5^{\circ} \mathrm{C} \Delta \mathrm{SST}$ bin. 


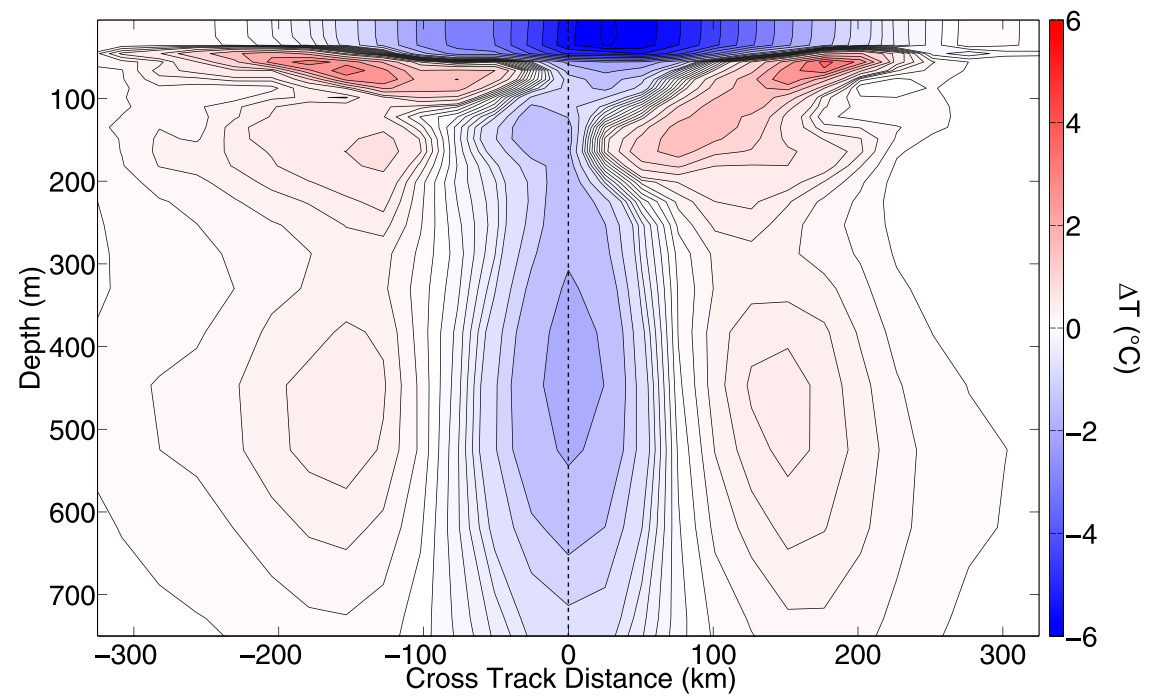

FIG. 8. Temperature anomaly cross section, taken across the wake of Typhoon Songda centered on $24.1^{\circ} \mathrm{N}, 131.6^{\circ} \mathrm{E}$. Positive (negative) cross track distances are to the right (left) of the track when oriented in the direction of storm translation.

For Frances, OHL reaches a maximum value of $2.6 \times$ $10^{20} \mathrm{~J}$ with an accompanying $\mathrm{OHU}$ of $2.9 \times 10^{20} \mathrm{~J}$, while Songda produces both OHL and OHU of $3.7 \times 10^{20} \mathrm{~J}$. OHU and OHL approximately balance in both cases, indicating that prior to restoration heat has been well conserved over the integration depth. TC windenhanced heat fluxes under the storm cool the ocean during TC passage, an effect that is underestimated in the uncoupled model as previously discussed. Direct extraction of heat by TC winds is a relatively small but nonnegligible contributor to TC-induced cooling when compared to vertical mixing, contributing less than $10 \%-15 \%$ to the cooling (Price 1981; Ginis 2002). While this lower heat extraction provides for warmer surface waters available for mixing by the TC and thus may elevate OHU values (Vincent et al. 2012a), its contribution to the anomalous heating is expected to be small. The maximum OHU and OHL for Frances are reached on 7 September, two weeks after Frances formed. Maximum OHU is $\sim 10 \%$ higher than OHL, indicating
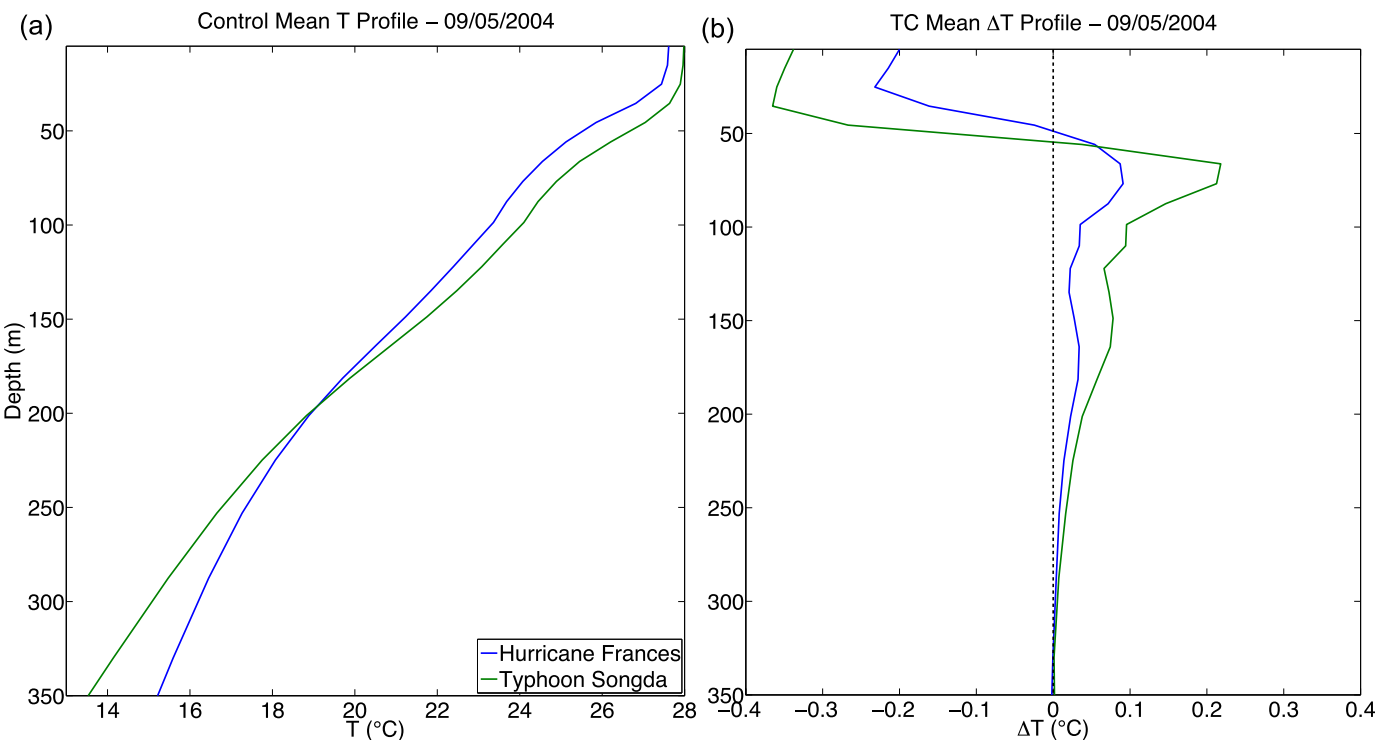

FIG. 9. (a) Temperature profile in the control experiment and (b) anomaly due to TC passage on 5 Sep 2004, averaged horizontally over the domains shown in Fig. 4. 


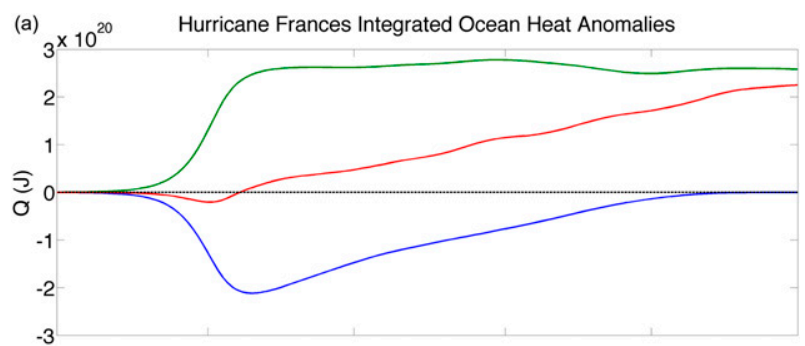

(b) ${ }_{3} \times 10^{20}$ Typhoon Songda Integrated Ocean Heat Anomalies

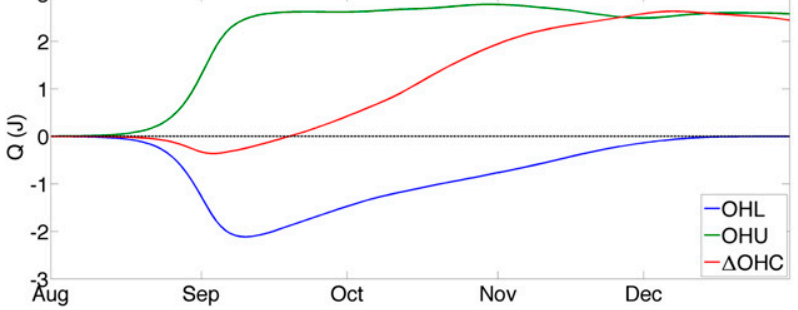

FIG. 10. Time series of the ocean heat loss, uptake, and content anomaly during and following passage of (a) Hurricane Frances and (b) Typhoon Songda, integrated across the North Atlantic and Pacific respectively from 1 Aug to 31 Dec 2004.

that restoration of upper ocean cooling has begun even as the TC continues to mix the ocean elsewhere. This is consistent with the SST restoration time scale previously discussed. The value of $\triangle \mathrm{OHC}$ was $\sim 75 \%$ of the maximum OHU for Frances, an artifact of the chosen averaging domain capturing cooling due to uncompensated deep upwelling.

OHL decays with an $e$-folding time of $39 \pm 2$ days for Frances and $44 \pm 2$ days for Songda. This recovery time is significantly longer than that of the SST, consistent with the additional time needed for solar insolation and mixing to restore temperatures in the ML. Reduction of SSTs in the cold wake result in a dampening of the outgoing latent, sensible, and longwave heat fluxes in Songda's wake (Fig. 11). This reduction creates an imbalance between outgoing heat fluxes and the unperturbed incoming shortwave radiation at the ocean surface, resulting in an accumulation of $3.5 \times 10^{20} \mathrm{~J}$ of anomalous heat input by the time the CML is restored. This positive anomalous surface heat flux nearly balances the $3.6 \times 10^{20} \mathrm{~J}$ of upper thermocline OHU, closing the heat budget in the mixed layer.

The impact of individual storms is compared to the values from Emanuel (2001). He found OHU from a single storm of $\sim 5 \times 10^{20} \mathrm{~J}$, given a wake of uniform width $(400 \mathrm{~km})$, length $(2000 \mathrm{~km})$, depth $(50 \mathrm{~m})$, and cooling $\left(3^{\circ} \mathrm{C}\right)$. The wakes of Frances and Songda have lengths $\sim 2000 \mathrm{~km}$, widths $\sim 400 \mathrm{~km}$, cooling to $\sim 50 \mathrm{~m}$, and average SST cooling of $3.25^{\circ}$ and $3.5^{\circ} \mathrm{C}$, respectively. While the wake characteristics are very similar, the $\mathrm{OHU}$ of Frances is $\sim 57 \%$ and Songda's $\sim 74 \%$ of Emanuel's estimates.

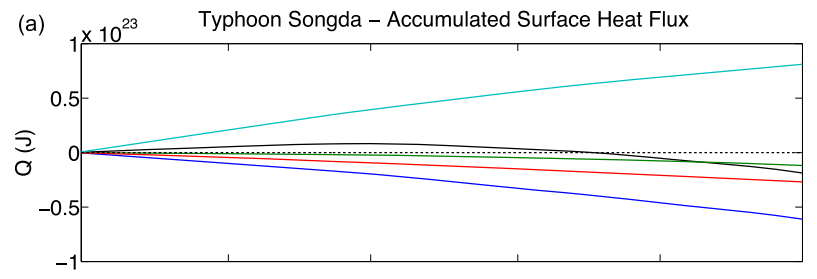

(b) $\times 10^{20}$ Typhoon Songda - Accumulated Surface Heat Flux Anomaly

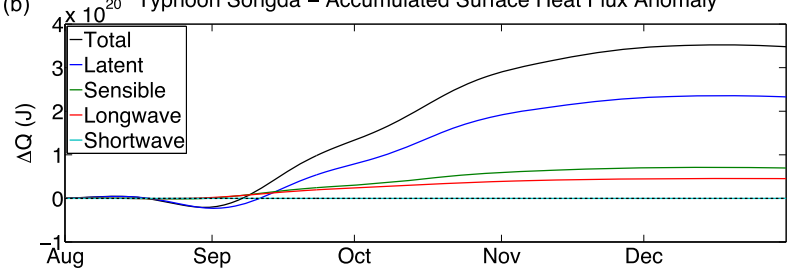

FIG. 11. Accumulated (a) surface heat flux and (b) heat flux anomaly following passage of Typhoon Songda, with positive values indicating a net heat gain by the ocean. Fluxes were integrated over the domain shown in Figs. 4c,d from 1 Aug to 31 Dec 2004.

The discrepancy is due to the spatial variability of the modeled cooling. The SST anomaly quickly falls off with distance from the core of the cold wake, cooling at depth quickly approaches zero past a depth of $\sim 30 \mathrm{~m}$, and the greatest cooling takes place only along the portion of the storm track where storm intensity and stratification are favorable. In light of this discrepancy, the idealized single storm estimate is considered an upper bound on storm impact.

\section{b. Global and basin ocean temperature response}

Shown in Fig. 12 are the SST and $\Delta$ SST fields on 1 October 2004 near the peak of northern TC activity. Strong cold wakes of recent TCs are present in the west Pacific (Typhoon Meari), east Pacific (Hurricane Javier), and North Atlantic (Hurricanes Jeanne, Karl, and Lisa). Weaker cooling is present where cold wakes have been partially restored in the weeks after storm passage (west Pacific Typhoons Songda and Aerie; east

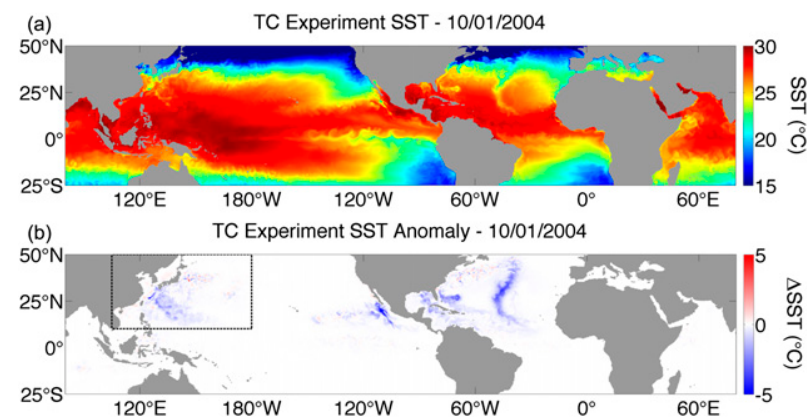

FIG. 12. Global (a) SST and (b) anomaly fields, demonstrating recent and recovering TC cold wakes in the North Atlantic, west Pacific, and east Pacific on 1 October 2004. The dashed box in (b) is the area over which the control volume budget in Fig. 17 is calculated. 

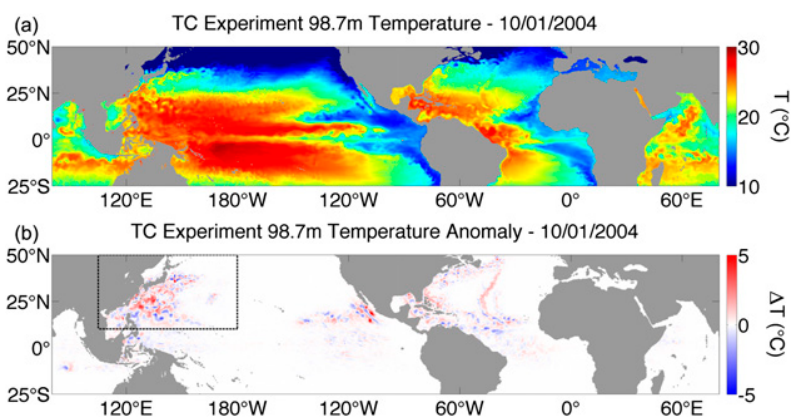

FIG. 13. Global (a) temperature and (b) anomaly fields at the 98.7-m depth level on 1 Oct 2004, demonstrating the mixing induced warming at depth, as well as warming and cooling from dynamical effects. The dashed box in (b) is the area over which the control volume budget in Fig. 17 is calculated.

Pacific Hurricanes Howard and Isis; North Atlantic Hurricanes Frances and Ivan). Figure 13 presents the accompanying subsurface temperature and temperature anomaly fields near $100 \mathrm{~m}$. Warming from mixing and downwelling is present throughout the TC forcing regions, persisting long after the surface cooling has been restored. Cooling due to Ekman pumping (upwelling) accompanies many of these warm anomalies, but the anomaly field at depth is dominated by warming.

Figure 14 shows TC-induced temperature anomalies averaged laterally across the basins described in Table 3, on 1 October 2004 and 31 May 2005. The different averaging areas are reflected in the differing $\Delta T$ axes between the global and hemisphere means (Figs. 14a,f) and basin means (Figs. 14b-e). The global anomaly (Fig. 14a) displays cooling to $\sim 40 \mathrm{~m}$ on 1 October with maximum warming at $\sim 60 \mathrm{~m}$ and extending deeper than $300 \mathrm{~m}$. By 31 May 2005, only the deep, persistent warming remains, with a maximum at $\sim 90 \mathrm{~m}$ and magnitude comparable to that in October.

The west Pacific, east Pacific, and North Atlantic have cooling on 1 October down to $\sim 50,30$, and $40 \mathrm{~m}$ respectively (Figs. 14b-d). West Pacific warming has a deeper and broader peak than either the North Atlantic or east (a)

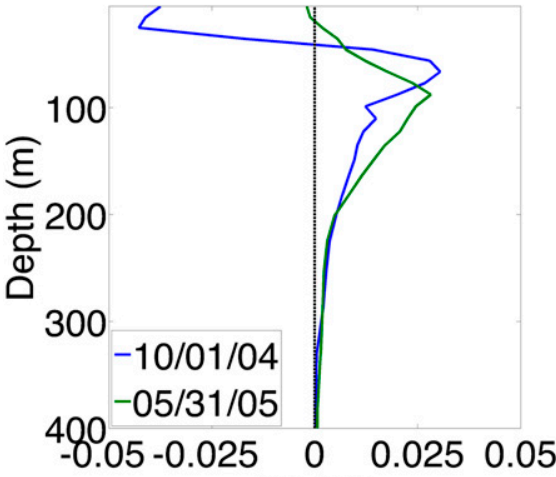
$\Delta \mathrm{T}\left({ }^{\circ} \mathrm{C}\right)$

(d)

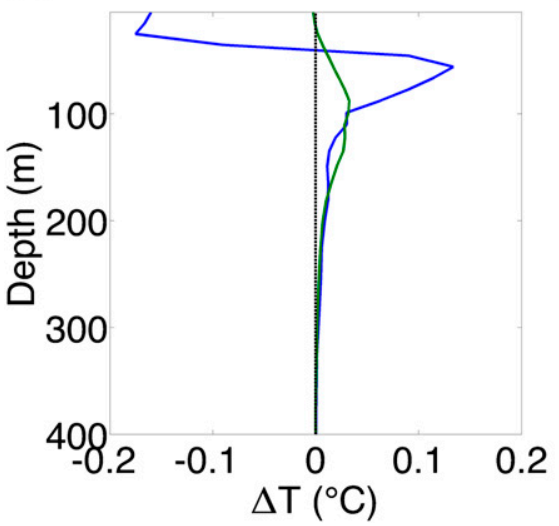

(b)

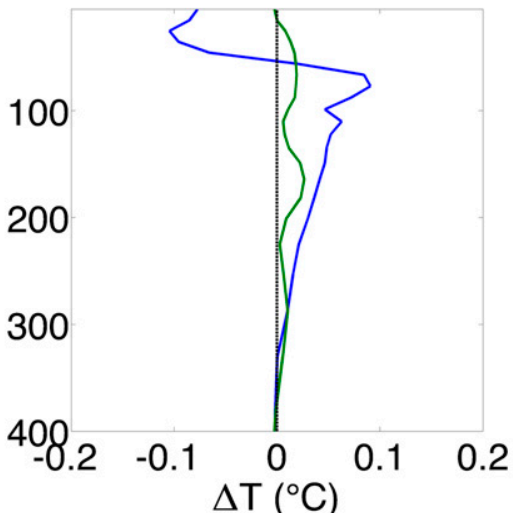

(e) North Indian Ocean

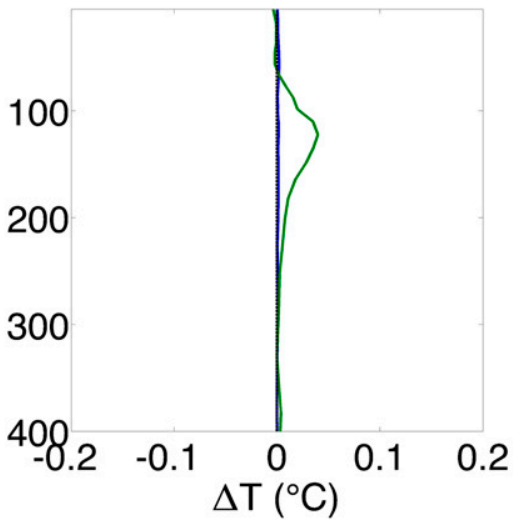

(c)

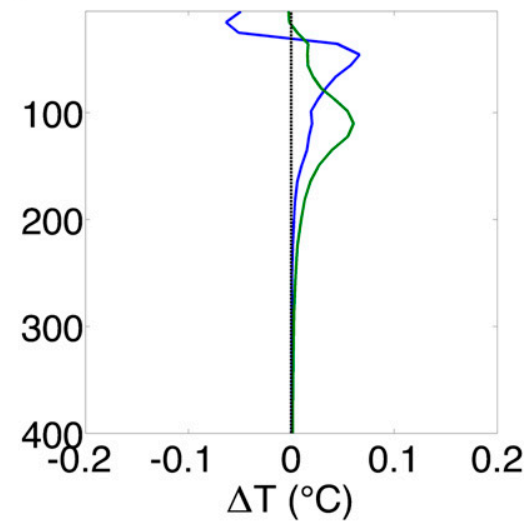

(f)

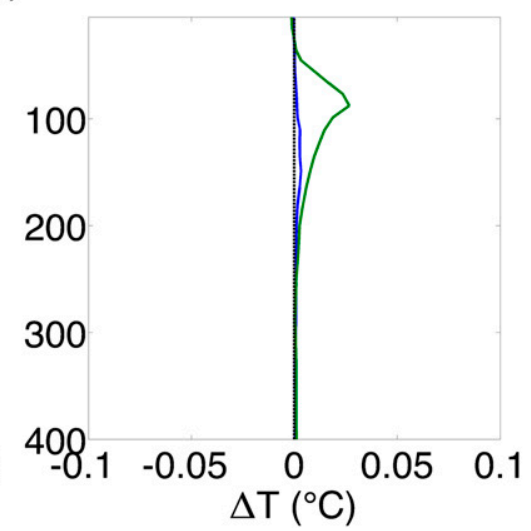

FIG. 14. Global and basin averaged temperature anomaly profiles at peak of northern TC activity (1 Oct 2004) and on 31 May 2005. Temperature axes differ between the (a) global, (b)-(e) basin, and (f) hemisphere profiles in order to account for the differences in averaging area (Table 3 ). 


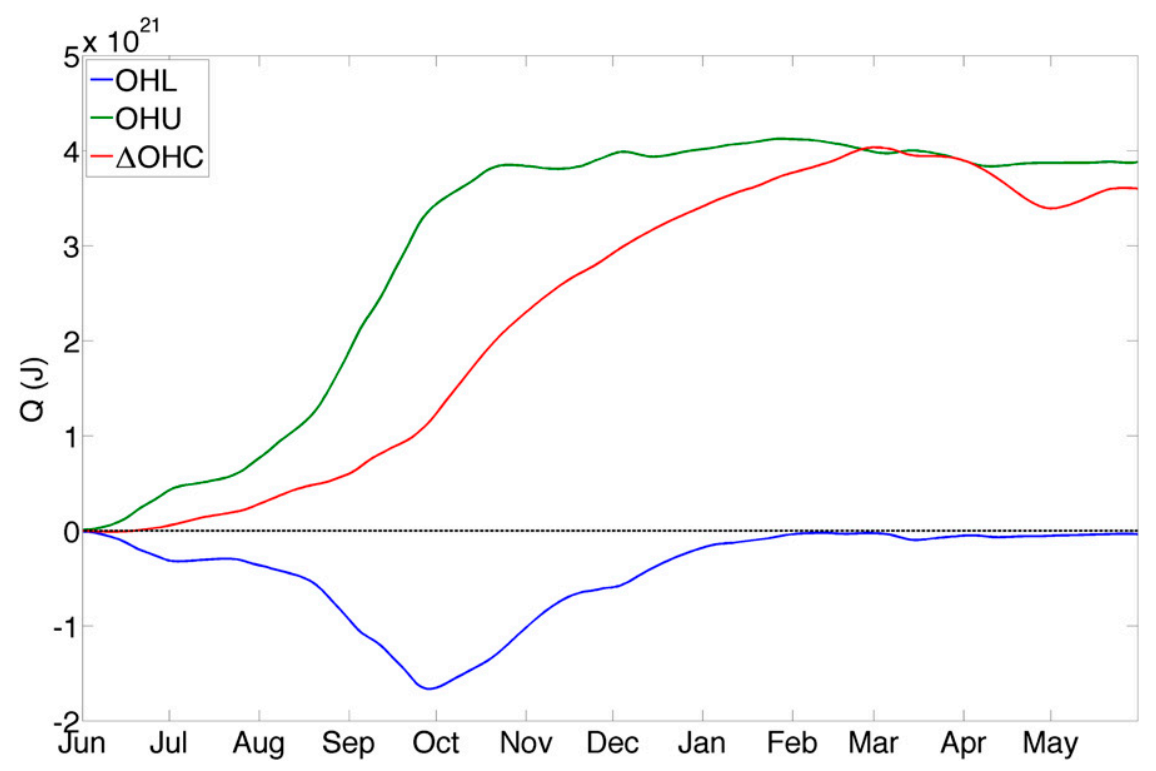

FIG. 15. Time series of the globally integrated OHL, OHU, and $\Delta \mathrm{OHC}$ from 1 Jun 2004 to 31 May 2005.

Pacific, while the east Pacific warming is both the shallowest and weakest. This interbasin variability is due to differences in TC forcing and local stratification, with those regions with the greatest forcing (west Pacific and North Atlantic) and with deeper mixed layers (west Pacific) having stronger and deeper warming.

Cooling in the North Atlantic has vanished by 31 May, with a weaker and deeper warm anomaly centered around $100 \mathrm{~m}$. The east Pacific warm anomaly on 31 May is nearly as strong as that on 1 October and has deepened by $\sim 60 \mathrm{~m}$. The west Pacific has two peaks of weaker persistent warming, one shallower $(\sim 50 \mathrm{~m})$ and the other deeper $(\sim 160 \mathrm{~m})$ than on 1 October. The reasons for these differences, especially the strong, deep 31 May warming in the east Pacific and weakened, bifurcated warming in the west Pacific, will be discussed in section 3e.

The North Indian Ocean, consistent with its weakened and offset TC season, has nearly zero subsurface accumulation on 1 October (Fig. 14e). By 31 May there is strong warming centered on $110 \mathrm{~m}$. In the Southern Hemisphere (Fig. 14f) there is a weak warming at depth on 1 October, centered on $150 \mathrm{~m}$. 1 October is before the start of austral TC activity, and so is not attributed to direct storm forcing. By 31 May, there is a sharp warming centered on $95 \mathrm{~m}$. The origin of this deep anomalous heating at times and locations removed from TC-induced mixing will be explored in section $3 \mathrm{e}$.

\section{c. Ocean heat uptake}

Figure 15 illustrates the OHL [Eq. (4a)], OHU [Eq. (4b)], and $\triangle \mathrm{OHC}[$ Eq. (3)] calculated from the global temperature anomaly profile (Fig. 14a). A 15-day low-pass filter is applied to the resulting time series, in order to emphasize seasonal to interseasonal trends. OHL increases slowly before accelerating with increased storm activity in August, reaching a peak of $1.7 \times 10^{21} \mathrm{~J}$ at the beginning of October. Global OHL subsequently decays until there is none remaining by February, indicating that on average the CML has been restored.

OHU temporal structure mirrors that of OHL through October, with anomalous heating increasing slowly through August, and then accelerating before leveling off at $\sim 4.1 \times 10^{21} \mathrm{~J}$, which is approximately $3 \%$ of the maximum amplitude of global seasonal $\mathrm{OHC}$ (Table 4), and somewhat lower than the heat uptake derived from SSH anomalies by Mei et al. (2013) (1.01 \pm $\left.0.46 \times 10^{22} \mathrm{~J}\right)$. OHU continues to increase slowly through January, before decreasing slightly to $3.9 \times$ $10^{21} \mathrm{~J}$. Increasing $\triangle \mathrm{OHC}$ lags $\mathrm{OHU}$ as in the Frances and Songda cases, with the difference between the two being equivalent to the OHL. February $\triangle \mathrm{OHC}$ values are comparable to OHU, by which time mean restoration of the global CML has occurred, giving confidence that $\mathrm{OHU}$ is capturing the warming anomaly in a globally averaged sense.

A globally averaged OHU rate can be derived from a linear fit to the OHU time series in Fig. 15. An annual OHU rate of $0.13 \pm 0.09 \mathrm{PW}$ is found for 1 June 2004-31 May 2005, with $R^{2}=0.69$. A seasonal rate of $0.47 \pm$ $0.02 \mathrm{PW}$ with $R^{2}=0.98$ is found by constraining the fit to the period of peak OHU (20 July-28 October 2004). This difference in uptake rate and $R^{2}$ supports the hypothesis 

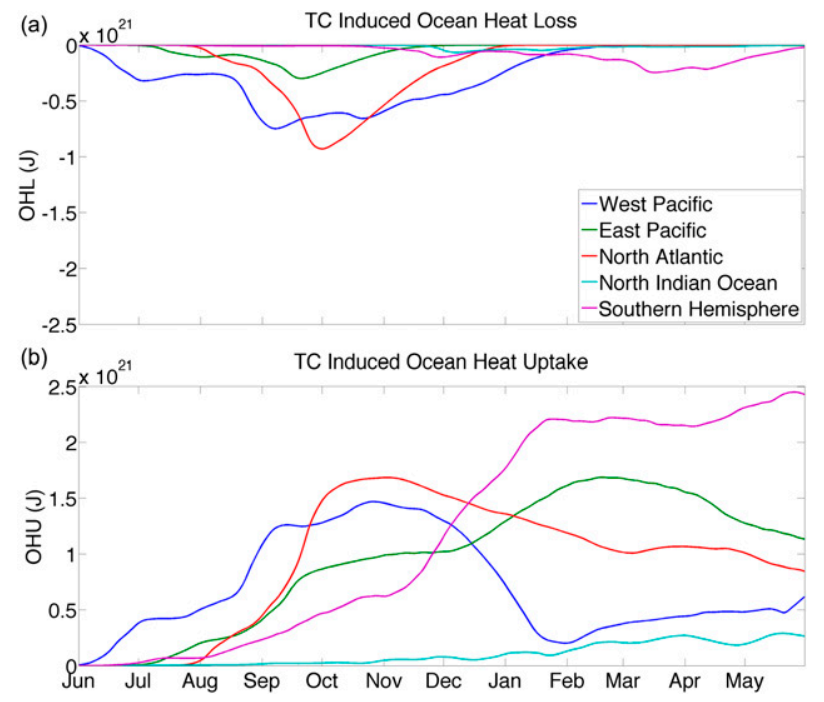

FIG. 16. Time series of (a) OHL and (b) OHU integrated over the individual ocean basins defined in Table 3 from 1 Jun 2004 to 31 May 2005.

that the effect of TC-induced heating on the ocean is poorly represented by a bulk annual heating rate.

As in past studies, we find the mean annual OHU rate to be a useful method of comparison, despite its acknowledged shortcomings in capturing the full spatial and temporal variability of TC thermocline heating. The annual OHU rate is consistent with the Argo float estimates of Park et al. (2011) $(0.19 \pm 0.03 \mathrm{PW})$ and the 0.15-PW rate of Jansen et al. (2010), which accounts for the effect of reventilation of thermocline thermal anomalies via the so-called "Stommel demon" associated with seasonal advection of subsurface heat anomalies around the subtropical gyre (Stommel 1979). The annual rate is lower than the findings of Sriver and Huber (2007) $(0.26 \mathrm{PW})$ and the "doubled wind" experiment of Sriver and Huber (2010) (0.3 PW), which they considered to be the most physically representative. Both rates are significantly lower than the estimates of Emanuel (2001) (1.4 \pm 0.7 PW), the peak values of Sriver et al. (2008) (0.6 PW), and the unventilated values of Jansen et al. (2010), again suggesting that a realistic representation of oceanic processes is critical in capturing TC-induced heating. Both the annual and seasonal rates are consistent with the recent estimates of Mei et al. (2013) $(0.32 \pm 0.15 \mathrm{PW})$.

Figure 16 shows the ocean basin cooling response to TC forcing, where OHL has been integrated across those basins defined in Table 3. The strongest OHL is seen in the North Atlantic (peaking at $8 \times 10^{20} \mathrm{~J}$ on 5 October) and the west Pacific (peaking at $7 \times 10^{20} \mathrm{~J}$ on 1 September). While its peak is lower, the west Pacific OHL is broader, consistent with the longer west Pacific TC season. The east Pacific and Southern Hemisphere have weaker OHL, peaking in late September and midApril respectively, again consistent with the timing and duration of direct TC forcing in those regions.

Basin integrated OHU is shown in Fig. 16b, with maxima shown in Table 4. Similar to the Frances, Songda, and Global OHU calculations, the initial heat uptake follows the structure of the accompanying OHL. North Atlantic OHU peaks in early October before gradually falling by $50 \%$ by 31 May 2005 . West Pacific OHU peaks in early November, at a lower value than the North Atlantic peak despite the greater local TC forcing. OHU in the west Pacific decreases rapidly between November and March, with less than $1 / 3$ of the maximum heating remaining on 31 May.

In contrast, east Pacific OHU peaks at $\sim 6 \times 10^{20} \mathrm{~J}$, and subsequently increases by $\sim 1 / 3$ after the conclusion of local TC activity. OHU in the Southern Hemisphere begins to accumulate during the northern summer, increasing rapidly in November before leveling off in February. There is a slight decrease in Southern Hemisphere OHU in March, followed by an increase that corresponds with local TC activity. The North Indian Ocean sees a small accumulation through the course of the northern winter.

Comparisons of basin peak $\mathrm{OHU}$ to $1 / 2$ the local summer-winter difference in $\Delta \mathrm{OHC}_{\text {season }}$ are presented in Table 4. In the dominant TC regions, TC-induced OHU can reach values up to $10 \%$ of the maximum seasonal amplitude. While the relative impact of TC OHU in the Southern Hemisphere is lower $(\sim 3 \%)$ it is still considerable given the lower direct TC forcing and size of the basin (Table 3 ).

The striking behavior of west Pacific, east Pacific, and Southern Hemisphere TC-induced OHU bears deeper analysis, specifically the reasons for their apparently compensatory variability. The heat anomaly budget for the region delineated by the dashed box in Figs. $12 \mathrm{~b}$ and $13 \mathrm{~b}$ is calculated (Fig. 17) to understand the reasons for the drastic drop in west Pacific OHU. Accumulated anomalous heating through the ocean surface results in a warming of the ocean. There is a strong and rapid accumulation of anomalous ocean heat transport

$$
\begin{gathered}
\Sigma \Delta \mathrm{OHT}(y, t)=c_{p} \rho_{o} \int_{x_{w}}^{x_{e}} d x \int_{0}^{H} d z \int_{0}^{t} d t^{\prime} \Delta(v T) \\
\Delta(v T)=v_{\mathrm{TC}} T_{\mathrm{TC}}-v_{\text {con }} T_{\text {con }}
\end{gathered}
$$

across the southern boundary. This southward heat export continues through January, with a peak value $\sim 2.75 \times$ $10^{21} \mathrm{~J}$ before turning northward. A considerably weaker and slower zonal export of anomalous heat occurs at the eastern boundary. The surface and advective forcing are 


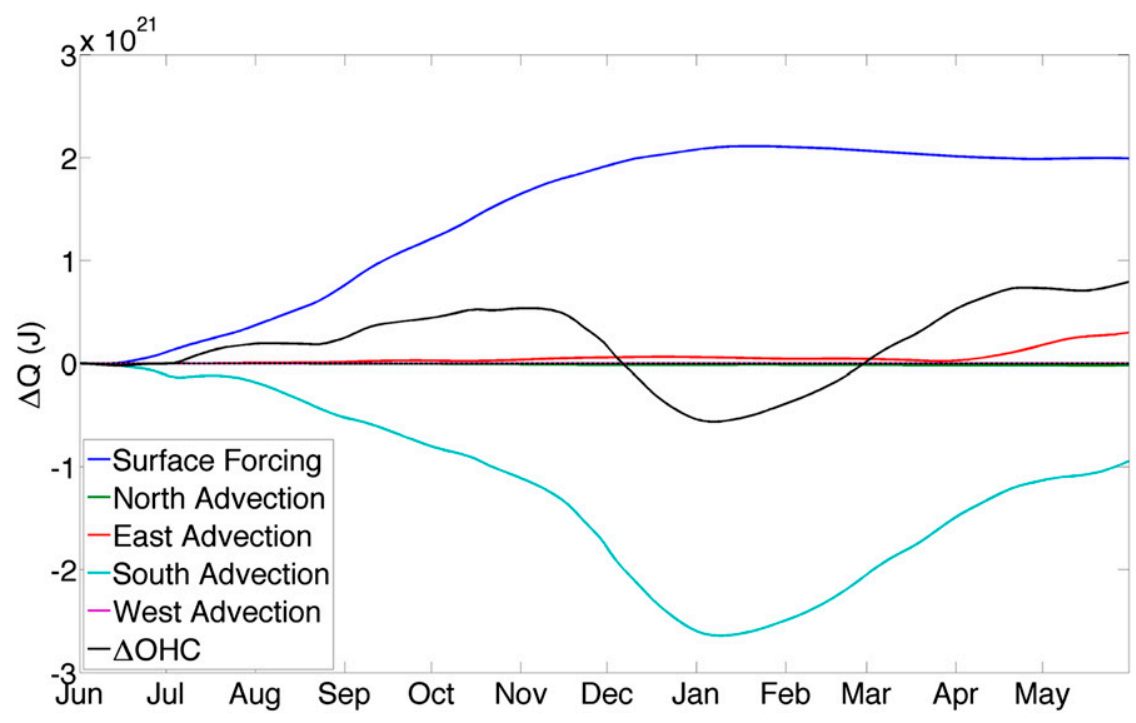

FIG. 17. Time series of the accumulated heat flux anomalies in the west Pacific TC forcing region, calculated for the domain outlined in Figs. 12b and 13b from 1 Jun 2004 to 31 May 2005. Positive values indicate an increase of heat within the control volume.

balanced by a regional change in OHC [Eq. (3)]. This analysis indicates that the drop in west Pacific OHU in Fig. 16b is consistent with a redistribution of anomalous heat from the subtropical to the tropical Pacific.

\section{d. Meridional transport}

Figure 18a shows the meridional distribution of $\mathrm{OHU}$, integrated $360^{\circ}$ zonally. Initially, anomalous heat accumulates between $10^{\circ}$ and $40^{\circ} \mathrm{N}$, before decreasing through the northern autumn and winter. OHU between $10^{\circ} \mathrm{S}$ and $10^{\circ} \mathrm{N}$, where there is little to no TC activity, increases as that north of $10^{\circ} \mathrm{N}$ attenuates. By 31 May the largest TC-induced heat anomaly is in the deep tropics, with a significant amount remaining in the northern subtropics and a smaller amount having accumulated in the southern subtropics due to austral TC activity. This distribution of OHU illustrates that the southward export of heat from TC forcing regions results in a convergence of heat in the tropics.

Heat export and convergence is more clearly seen in Fig. 18b, where Eq. (5a) has been integrated around the globe every $10^{\circ}$ from $30^{\circ} \mathrm{S}$ to $30^{\circ} \mathrm{N}$, producing time series of the accumulated meridional TC induced heat transport anomaly. There is a clear southward transport in the Northern Hemisphere starting in late summer. This OHT anomaly strengthens between $20^{\circ}$ and $10^{\circ} \mathrm{N}$ before penetrating across the equator. By $10^{\circ} \mathrm{S}$ there is no further transport accumulation, confirming the convergence of heat in the equatorial region.

The temporal structure and magnitude of the global OHT anomaly accumulation across $10^{\circ} \mathrm{N}$ is consistent with that across the southern boundary of the west Pacific control volume analyzed in Fig. 17, establishing that the equatorial $\triangle \mathrm{OHT}$ convergence is dominated by export of TC induced OHU out of the subtropical west Pacific. For this reason, the remainder of the analysis focuses on the west Pacific transport and circulation. While there is a significant decrease in $\mathrm{OHU}$ in the North Atlantic between November and May $(\sim 50 \%)$, it is not associated with export of heat to the tropical Atlantic. Rather, this decrease is likely due to the reventilation mechanism of Jansen et al. (2010).

\section{e. Subtropical-tropical interaction}

The currents in the west Pacific upper thermocline are shown in Fig. 19. Zonal and meridional currents are averaged from 56 to $253 \mathrm{~m}$ to capture the flow field over the depths where TC mixing deposits heat. The region shown contains nearly all of the west Pacific TC activity (Fig. 2). Zonal flow is predominantly westward, carrying TC-induced heat anomalies toward the western boundary, where they enter either the Kuroshio to be advected poleward or the Mindanao Current to be advected into the deep tropics. Whether a water mass enters the Kuroshio or Mindanao is determined by its latitude upon reaching the western boundary and the location of the bifurcation of the North Equatorial Current (NEC).

The location of the NEC bifurcation varies seasonally, consistent with the observational findings of $\mathrm{Qu}$ and Lukas (2003), who hypothesized that changes in local Ekman pumping associated with monsoonal winds alter the circulation such that the bifurcation reaches its northernmost location between November and 

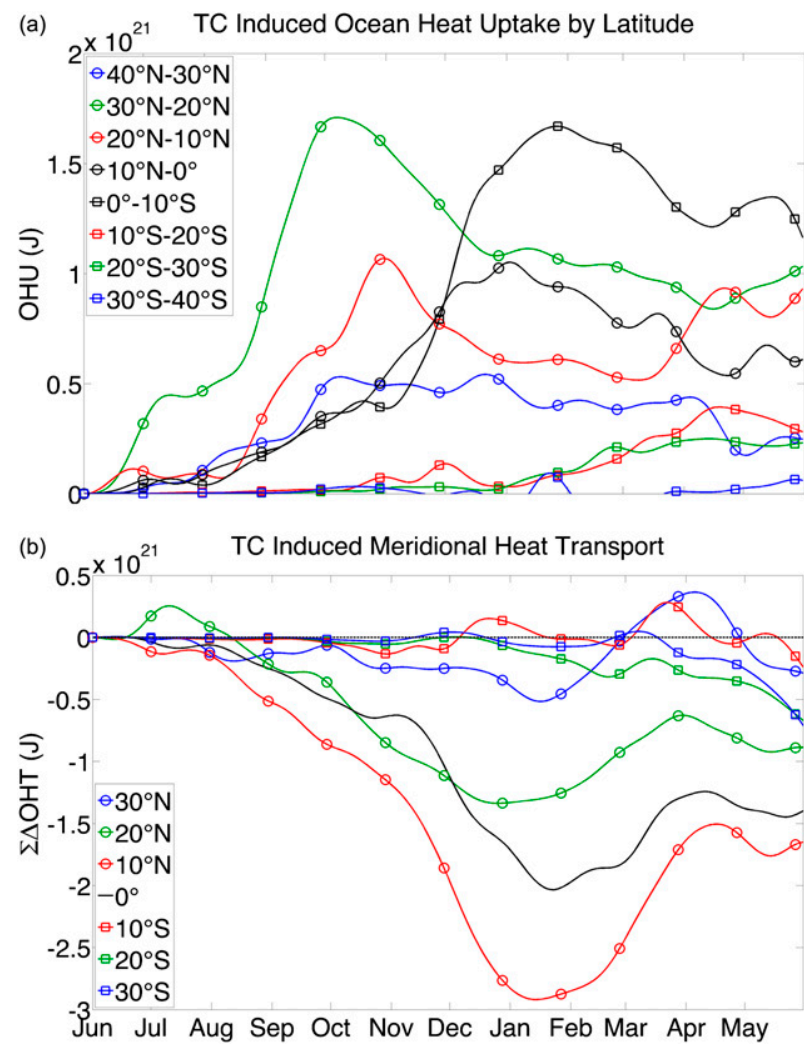

FIG. 18. (a) Ocean heat uptake integrated by latitude and (b) accumulated meridional heat transport anomaly [Eq. (5a)] across the boundaries of those bands from 1 Jun 2004 to 31 May 2005. Negative values in (b) indicate southward transport.

December, before migrating south through July. The bifurcation point is around $15^{\circ} \mathrm{N}$ between August and October (Fig. 19a), $16^{\circ} \mathrm{N}$ between November and January (Fig. 19b), and as far south as $12^{\circ} \mathrm{N}$ between February and April (Fig. 19c). Times when the bifurcation is farther to the north correspond with elevated anomalous heat transport into the tropics, with the proportion of midgyre waters flowing into the Mindanao elevated relative to the annual mean.

Warm anomalies are advected equatorward as part of the subtropical cell (McCreary and Lu 1994). Large-scale southward deflection of the NEC between $125^{\circ}$ and $130^{\circ} \mathrm{E}$ in the November-January period further enhances the flow into the Mindanao, corresponding with the period of greatest $\triangle \mathrm{OHT}$ into the tropics. The late winter period February-April sees a relaxation of the currents consistent with the reduced wind stress curl during the southwest monsoon. Meridional flow in the midgyre region $\left(130^{\circ}-150^{\circ} \mathrm{E}\right)$ is now predominantly northward, with waters from the tropics penetrating the gyre interior and entering the Kuroshio. This seasonality in the regional flow results in a reversal of the total regional OHT integrated along the equator and $10^{\circ} \mathrm{N}$, in phase
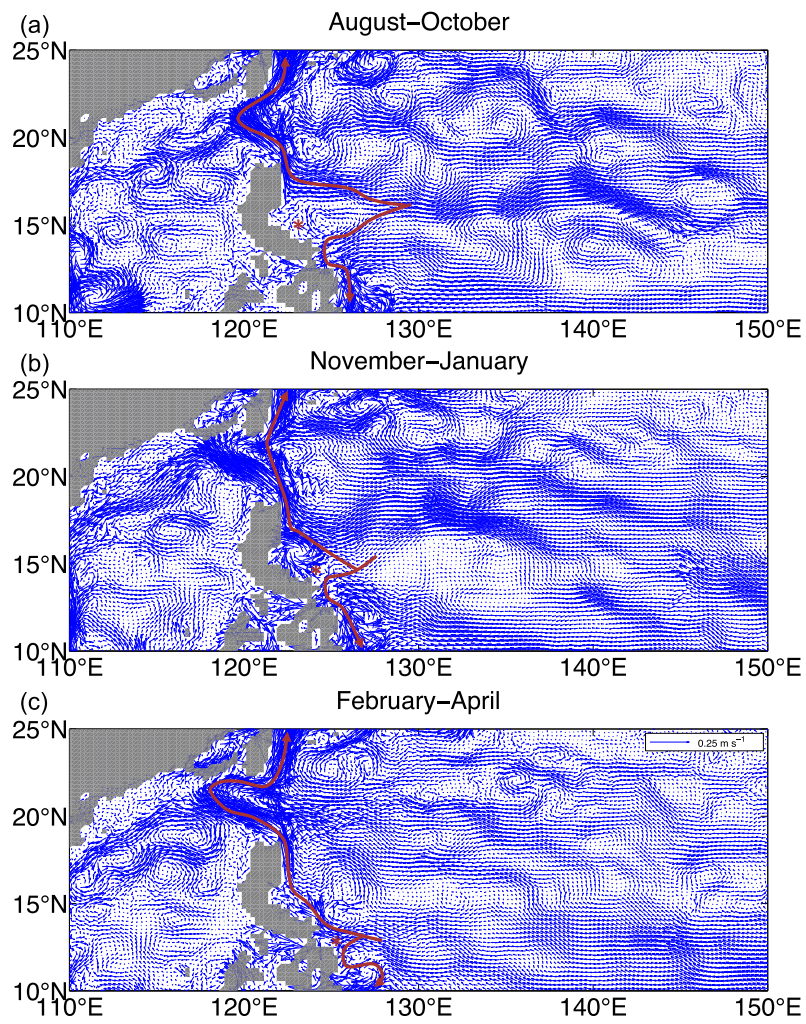

FIG. 19. Thermocline averaged $(56-253 \mathrm{~m})$ currents in the west Pacific averaged during the period of (a) peak TC forcing, (b) greatest southward advection, and (c) reversal. Red stars approximate the bifurcation of the North Equatorial Current into the Kuroshio and Mindanao Current. Red lines are a schematic representation of water parcel trajectories into the Kuroshio to the north and the Mindanao Current to the south.

with the reversal in $\Delta \mathrm{OHT}$ seen in Figs. 17 and $18 \mathrm{~b}$, providing a physical explanation for the return of anomalous heat to the subtropics.

The model representation of the mean annual equatorial circulation averaged from 56 to $330 \mathrm{~m}$ is shown in Fig. 20. The current experimental design allows for a reasonable representation of the low-latitude western boundary currents in the Pacific, and produces a wellresolved Indonesian Throughflow. For example, the Makassar Strait, one of the narrowest choke points in the region, has an $\sim 10$ grid point representation at this resolution. The rapid flow in the Mindanao is clearly displayed, feeding into the Indonesian Throughflow west of $120^{\circ} \mathrm{E}$ and the Equatorial Undercurrent (EUC) east of the Philippines and eastward into the open Pacific. We estimate that of the $\sim 2.9 \times 10^{21} \mathrm{~J}$ of accumulated $\Delta \mathrm{OHT}$ from the Mindanao Current, nearly $0.9 \times 10^{21} \mathrm{~J}$ enters the Indonesian Throughflow via the Makassar Strait, with the rest progressing east via the EUC. This partitioning of the anomalous heat transport between the Indonesian Throughflow and EUC is consistent with 
(a)

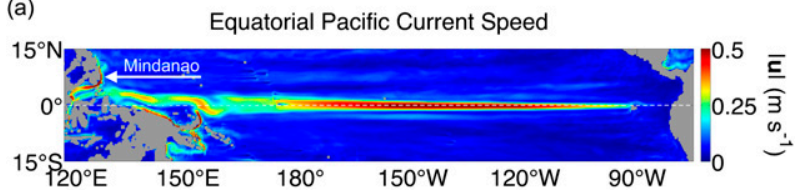

(b)

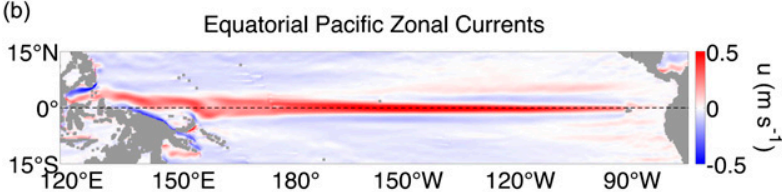

(c)

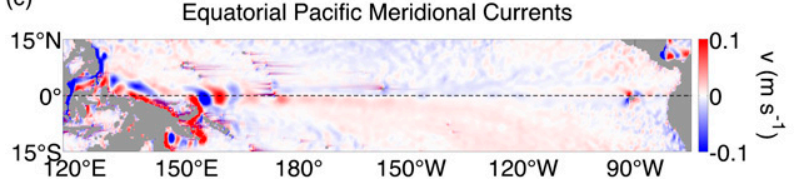

FIG. 20. Currents in the equatorial Pacific, averaged from 1 Jun 2004 to 31 May 2005 and over the 56-330-m depth levels: (a) current speed, (b) zonal currents, and (c) meridional currents. The scale of meridional currents is reduced due to the greater strength of zonal flow in the tropics.

observations of the mean volume transport, where $9.3 \pm$ $2.5 \mathrm{~Sv}\left(1 \mathrm{~Sv} \equiv 10^{6} \mathrm{~m}^{3} \mathrm{~s}^{-1}\right)$ passes through the Makassar Strait (Gordon et al. 1999) out of the 25-35 Sv of mean southward transport in the Mindanao (Lukas 1988). The MOM representation of the EUC reaches speeds exceeding $1 \mathrm{~m} \mathrm{~s}^{-1}$ and is sharply sloped zonally along isopycnals, consistent with observations (e.g., see Fig. 13 in Griffies et al. 2009). Advection by the EUC would serve as a rapid mechanism of zonal OHU redistribution should TC-induced warm anomalies reach the undercurrent. On the eastern boundary, the coastal undercurrent off of Peru (Brockmann et al. 1980) would serve to advect anomalous heat from the tropical East Pacific north of the equator into the Southern Hemisphere, accounting for the offsetting changes in East
Pacific and Southern Hemisphere OHU (Fig. 16a) seen in April.

For TC heat anomalies to enter the undercurrent, water parcels must reach nearly 100-200-m depth by the time they enter the deep tropics. Figure 21 shows temperature anomalies averaged from $120^{\circ}-150^{\circ} \mathrm{E}$, that being the dominant region of equatorward transport. Most anomalous heat is deposited north of $15^{\circ} \mathrm{N}$ and below $60 \mathrm{~m}$. Meridional flow takes place primarily along isopycnal pathways, subducting water masses as they are advected equatorward (Rothstein et al. 1998; McCreary and $\mathrm{Lu}$ 1994). Advection of warm anomalies is inferred along the $1031-1032 \mathrm{~kg} \mathrm{~m}^{-3}$ isopycnals in Fig. 21a during the autumn, causing the anomalies to deepen until they intersect with the EUC. Relatively little anomalous heat remains in the western Pacific south of $10^{\circ} \mathrm{N}$, implying that the EUC is in fact exporting heat eastward. Some heat anomalies remain at depth in the subtropics during the winter to be ventilated by winter mixed layer deepening (Fig. 21b). A persistent upwelling centered around $15^{\circ} \mathrm{N}$ and flanking downwelling is a prominent feature seen in Fig. 21a, resulting from multiple TCs propagating predominantly westward in the region (Fig. 2) and subsequent reinforcement of the storm-induced Ekman pumping. This cumulative Ekman pumping produces anomalous zonal currents due to the thermal wind balance, directed westward on the northern and eastward on the southern edge of the upwelling region. These currents are expected to be weaker than the mean currents associated with the subtropical gyre, which are primarily responsible for advection of the TC-induced heat anomalies.

Figure 22 presents the mean monthly temperature anomalies from $5^{\circ} \mathrm{S}$ to $5^{\circ} \mathrm{N}$. TC-induced warm anomalies generated in the subtropics reach the tropics between late July and early August (Figs. 22b,c). (a)

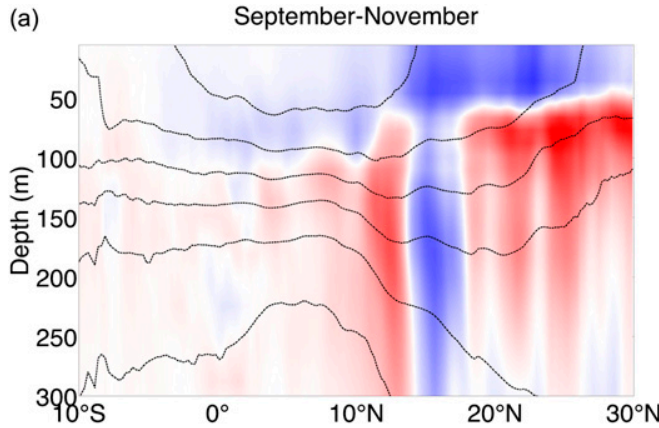

(b)

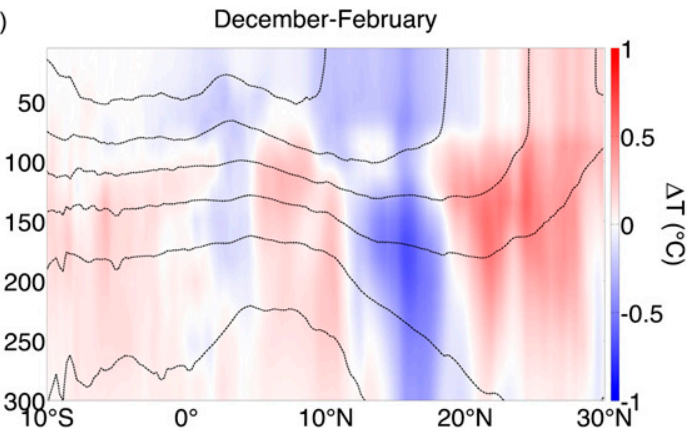

FIG. 21. West Pacific temperature anomalies averaged over the region of southward advection $\left(120^{\circ}-150^{\circ} \mathrm{E}\right)$, with average isopycnals from the same period superimposed, for (a) September-November and (b) December-February. Isopycnals based on potential density referenced to the surface are averaged over the same region and period as temperature anomalies, and range from 1030 to $1035 \mathrm{~kg} \mathrm{~m}^{-3}$ in $1 \mathrm{~kg} \mathrm{~m}^{-3}$ increments. 


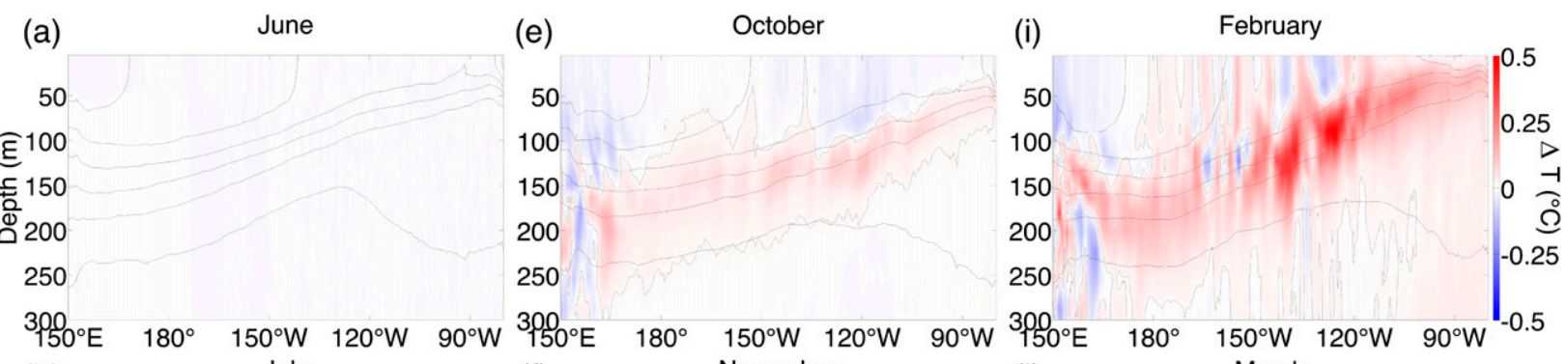

(b) July (f)
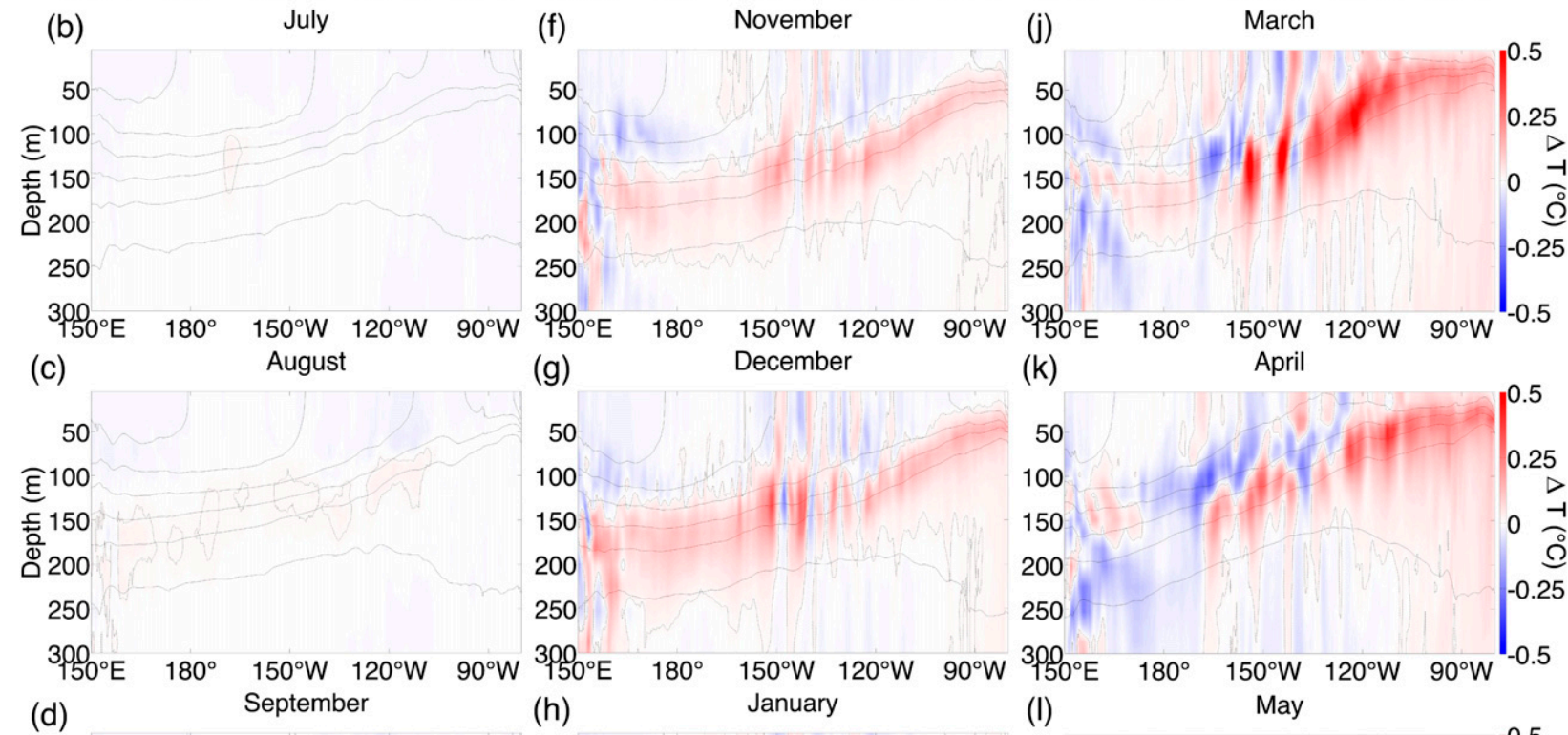

(g)

December
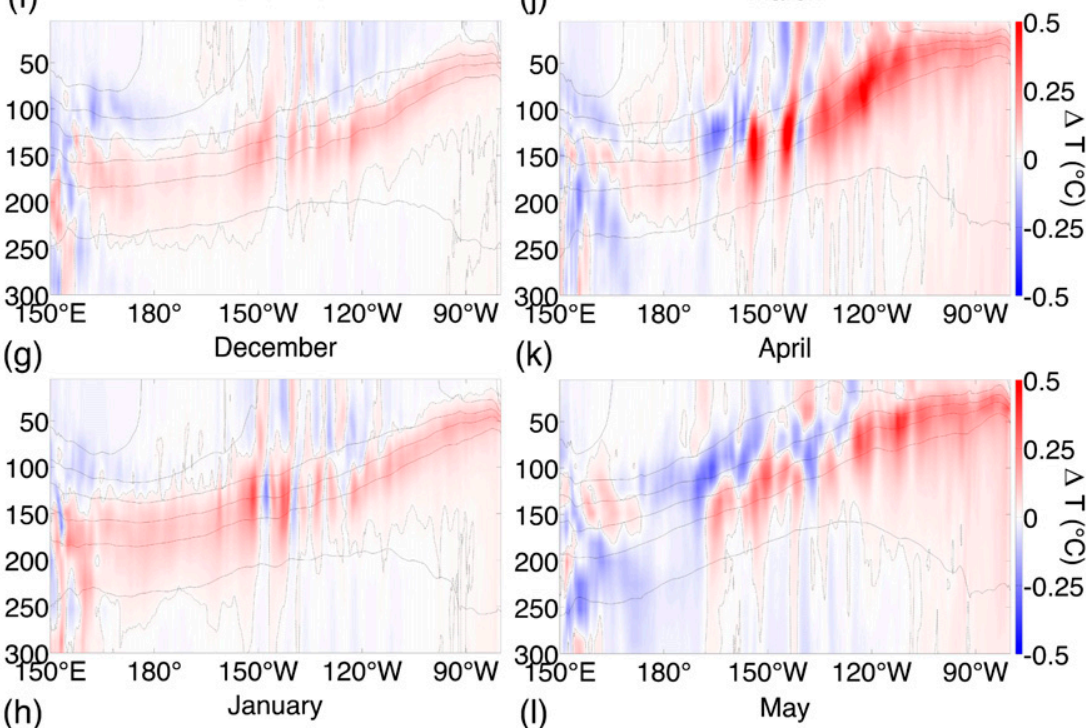

(k)

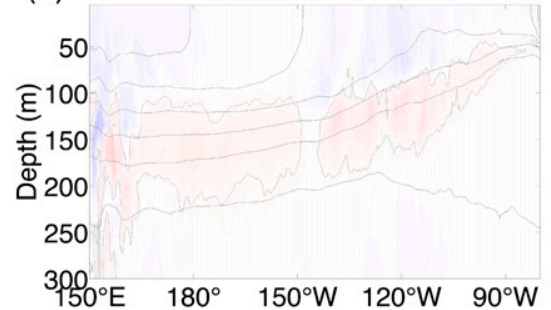

(h)
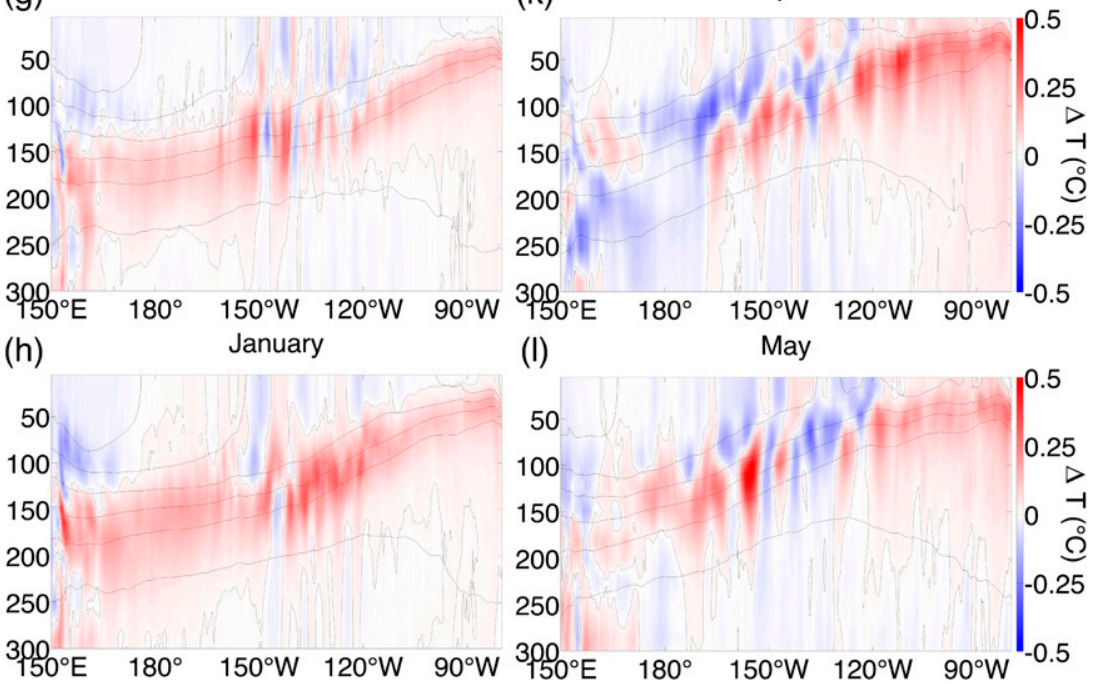

FIG. 22. Monthly averaged temperature anomalies averaged from $5^{\circ} \mathrm{S}$ to $5^{\circ} \mathrm{N}$ in the Pacific Equatorial Undercurrent, with average isopycnals from the same period superimposed. Isopycnals based on potential density referenced to the surface are averaged over the same region and period as temperature anomalies, and range from 1030 to $1035 \mathrm{~kg} \mathrm{~m}^{-3}$ in $1 \mathrm{~kg} \mathrm{~m}^{-3}$ increments.

Advection within the EUC moves the warm anomalies entering the equatorial Pacific eastward. Warm anomalies can also be carried by eastward-propagating Kelvin and Yanai waves excited by west Pacific TCs as demonstrated by Sriver et al. (2013). The phase speeds of the first and second baroclinic Kelvin modes are similar to the EUC velocity. The vertically coherent warm and cold anomalies present in Figs. 22e-1 are due to the phase differences in tropical instability waves between our two simulations. These phase differences are not expected to contribute to the zonal heat transport.

Warm anomalies reach the east Pacific by midautumn, shoaling along the thermocline (Figs. 22a-e).
Thermocline warm anomalies in the west Pacific are significantly diminished between March and May while persisting in the east Pacific (Figs. 22j-1). This behavior is consistent with the seasonal generation of TC-induced warm anomalies in the west Pacific.

Rapid relocation of TC-induced warm anomalies via the west Pacific subtropical cell, Mindanao Current, EUC, and equatorial waves explains the rapid decrease of OHU in the west Pacific between November and February seen in Fig. 16b. This connection between west Pacific TC activity and warming of east Pacific tropical thermocline waters occurs on time scales of less than one year. 


\section{Discussion}

The interaction of tropical cyclones with the ocean produces a nonnegligible heating of the thermocline with potential implications for the ocean climate system. Although tropical cyclones (TCs) are a global phenomenon, viewing the impact of TCs on the ocean on a regional basis sheds light on the physical mechanisms driving the generation and redistribution of TC-induced ocean heat uptake (OHU). Our estimates of global heat uptake magnitude and rates are consistent with the results of recent observational and modeling studies. We find that TC-induced heat uptake can augment the basin heat content by up to $10 \%$ of the maximum local seasonal amplitude in those basins with the greatest storm activity. Results from our study are subject to uncertainties associated with model formulation (e.g., parameterizations), grid resolution, and biases due to the lack of atmospheric coupling. We therefore recommend further examinations in global eddying simulations of the mechanisms for TC-induced heat transport and quantitative estimates of $\mathrm{OHU}$.

Because of the single year of model integration and analysis, we are unable to address questions related to the poleward export of anomalous heating through the Atlantic meridional overturning circulation predicted by previous studies (Emanuel 2001; Jansen et al. 2010; Sriver and Huber 2010; Manucharyan et al. 2011; Scoccimarro et al. 2011). Rather, our analysis identifies a rapid equatorial convergence of heat through the shallower and more rapid wind-driven west Pacific subtropical cell. The intense currents near the western boundaries of the ocean basins play a key role, especially in the west $\mathrm{Pa}$ cific. We do not see this behavior as contradicting findings of poleward transport, but as taking place in parallel and on shorter time scales.

TC-induced warm anomalies are efficiently exported to the tropics, where they are moved zonally into the tropical east Pacific by the EUC and equatorial waves. This behavior is consistent with the findings of Manucharyan et al. (2011), but shows strong heat accumulation in the east Pacific over shorter time scales. Convergence of anomalous TC heating in the equatorial east Pacific could have climate implications on interannual time scales, with the possibility for modulation of the El Niño-Southern Oscillation (ENSO) (Fedorov et al. 2010).

Our analysis of a single season has provided insight into the potential effect of tropical cyclones on the ocean climate system. Nonetheless, many questions remain unaddressed. While we have traced some of the dominant pathways by which anomalous heat is redistributed, a further analysis of the physics of this transport is warranted, as is the study of the fate of these anomalies through subsequent TC seasons. Future work should also address how representative the impact of 1 June 2004-31 May 2005 TC activity is, and if there is a multiyear accumulated effect of storm induced heating. If this heating does continue to accumulate, the mechanisms by which the ocean eventually discharges it in order to remain in thermodynamic balance must be explained, be it by reventilation or interaction with and discharge by ENSO or other large-scale climate processes.

Acknowledgments. We thank WeatherPredict Consulting Inc. for providing financial support. We are also grateful to GFDL and Oak Ridge National Laboratory for providing us with the needed computational resources and technical assistance. We thank Whit Anderson and Zhi Liang at GFDL for their help throughout this project with the simulations and to Mike Winton for his support. We also thank Jae-Hun Park for helpful discussion, and Richard Yablonsky and Biju Thomas for development support.

\section{APPENDIX}

\section{Wind Formulation}

TC winds are based on the NHC/JTWC TCVitals database, as seen in Tables 1 and 2 and described by Trahan and Sparling (2012). This database provides representation of the storms location, intensity, and structure produced every $6 \mathrm{~h}$ as a real-time analysis of all available data. The specific parameters utilized are the longitude and latitude of the center of storm circulation, the maximum sustained wind speed (MWS), radius of maximum wind (RMW), central sea level pressure $\left(p_{c}\right)$, environmental sea level pressure $\left(p_{o}\right)$, radius of outermost closed isobar $\left(R_{\mathrm{cls}}\right)$, and the radii at which the sustained winds reach values of 18 and $26 \mathrm{~m} \mathrm{~s}^{-1}$ in the northeast, southeast, southwest, and northwest quadrants of the storm $\left(R_{18}\right.$ and $\left.R_{26}\right)$. Each of these parameters is linearly interpolated in time, along the storm track, to the current model time step, in order to provide a coherent storm structure at all times.

Based on the presence of the $R_{18}$ and $R_{26}$ parameters, an asymmetric empirical wind field is calculated that accounts for the differing wind radii in each quadrant of the storm (Bender et al. 2007). For each location in space, the radial distance from the storm center, $r$, and angular departure from due north, $\alpha$, are determined. Note that $R_{18}$ and $R_{26}$ are interpolated along lines of constant $r$ to the current $\alpha$. Based on which of these radii are present for the current time (having a value greater than zero in the best-track database), a scaling radius and wind speed are derived for the current angle $\alpha$ 


$$
R_{1}(\alpha)=\left\{\begin{array}{lll}
\frac{1}{2}\left[R_{18}(\alpha)+R_{26}(\alpha)\right] & \text { if } & R_{18}>0 \& R_{26}>0 \\
R_{18}(\alpha) & \text { if } & R_{26}<0 \\
R_{26}(\alpha) & \text { if } & R_{18}<0
\end{array}\right.
$$

$$
V_{1}(\alpha)=\left\{\begin{array}{lll}
22 \mathrm{~m} \mathrm{~s}^{-1} & \text { if } & R_{18}>0 \& R_{26}>0 \\
18 \mathrm{~m} \mathrm{~s}^{-1} & \text { if } & R_{26}<0 \\
26 \mathrm{~m} \mathrm{~s}^{-1} & \text { if } & R_{18}<0
\end{array}\right.
$$

which are used to calculate an angularly dependent $e$-folding radius, $b$, for the wind speed

$$
b(\alpha)=\frac{\mathrm{RMW}-R_{1}(\alpha)}{\ln \left[\frac{V_{1}(\alpha)}{\mathrm{MWS}}\right]}
$$

and finally arrive at a wind speed profile that is linear within the RMW, and decays exponentially without:

$$
U_{10}(r, \alpha)=\operatorname{MWS}\left\{\begin{array}{lll}
\frac{r}{\mathrm{RMW}} & \text { if } & r<\mathrm{RMW} \\
e^{(\mathrm{RMW}-r) / b(\alpha)} & \text { if } \quad r \geq \mathrm{RWM}
\end{array} .\right.
$$

This wind speed magnitude is decomposed into tangential $\left(U_{\mathrm{tan}}\right)$ and radial $\left(U_{\mathrm{rad}}\right)$ components as

$$
\begin{aligned}
& U_{\tan }(r, \alpha)=U_{10}(r, \alpha) \cos [\theta(r)], \\
& U_{\text {rad }}(r, \alpha)=-U_{10}(r, \alpha) \sin [\theta(r)],
\end{aligned}
$$

where $\theta(r)$ is an empirically derived angle represent the proportion of the wind directed in the radial direction (inflow) versus tangentially. These radial and tangential winds are then converted into zonal and meridional components as

$$
\begin{aligned}
u(r, \alpha) & =U_{\text {rad }} \cos (\alpha)-U_{\tan } \sin (\alpha) \\
& =-U_{10} \sin [\alpha+\theta(r)], \\
v(r, \alpha) & =U_{\text {tan }} \cos (\alpha)-U_{\text {rad }} \sin (\alpha) \\
& =U_{10} \cos [\alpha+\theta(r)] .
\end{aligned}
$$

In the absence of the angularly dependent structure data, the axisymmetric wind profile of Holland (1980) is used instead. RMW, MWS, and pressure gradient $\Delta p=$ $\left(p_{c}-p_{o}\right)$ are used to calculate the scaling variables

$$
\begin{aligned}
& A=\mathrm{RMW}^{B}, \\
& B=\mathrm{MWS}^{2} e \frac{\rho_{a}}{\Delta p},
\end{aligned}
$$

where $\rho_{a}$ is the density of dry air $\left(\sim 1.28 \mathrm{~kg} \mathrm{~m}^{-3}\right)$. These two parameters are then used to calculate a wind speed magnitude at each grid point

$$
U_{10}(r)=\left[A B\left(\frac{e^{-A / r^{B}}}{\rho_{a} r^{B}}\right)+\frac{r^{2} f^{2}}{4}\right]^{1 / 2}-\frac{r f}{2},
$$

where $r$ is the current distance from the center of circulation. As above, the wind speed magnitude is then decomposed into zonal and meridional components. These wind speed vectors are then augmented by onehalf of the storm's translation speed, in order to capture some portion of the asymmetry caused by the superposition of the storms circulation and forward motion.

Synthetic wind speeds are generated for each storm in the best-track database in sequence, on a $1 / 6^{\circ}$ resolution equirectangular grid, using the appropriate formulation. To minimize the overlap of storm profiles and problems in the tail of the Holland (1980) wind profile as the Coriolis parameter $f$ tends to zero, the winds are constrained to uniformly vanish outside of an imposed radius equal to twice the $R_{\text {cls }}$. This radius is chosen because, physically, $R_{\mathrm{cls}}$ should roughly represent the size of the closed, recirculation vortex, but somewhat underestimates the distance at which the synthetic TC winds are uniformly smaller than the CORE-II winds.

Each storm is projected onto the ocean model grid. A point-by-point comparison is then made between the synthetic TC and specified CORE-II wind speed magnitudes. For those points where the TC forcing is greater, the meridional and zonal wind speed components from the CORE forcing are replaced by those from the synthetic storm. In this way, relatively smooth embedding of the empirically generated storms into an atmospheric dataset that previously lacked strong TC forcing is achieved.

\section{REFERENCES}

Bender, M. A., I. Ginis, R. Tuleya, B. Thomas, and T. Marchok, 2007: The operational GFDL Coupled Hurricane-Ocean Prediction System and a summary of its performance. Mon. Wea. Rev., 135, 3965-3989, doi:10.1175/2007MWR2032.1.

Black, P. G., and Coauthors, 2007: Air-sea exchange in hurricanes: Synthesis of observations from the Coupled Boundary Layer Air-Sea Transfer experiment. Bull. Amer. Meteor. Soc., 88, 357-374, doi:10.1175/BAMS-88-3-357.

Boccaletti, G., R. Ferrari, and B. Fox-Kemper, 2007: Mixed layer instabilities and restratification. J. Phys. Oceanogr., 37, 22282250, doi:10.1175/JPO3101.1.

Brockmann, C., E. Fahrbach, A. Huyer, and R. L. Smith, 1980: The poleward undercurrent along the Peru Coast: $5^{\circ}$ to $15^{\circ} \mathrm{S}$. DeepSea Res., 27, 847-856, doi:10.1016/0198-0149(80)90048-5.

Cummings, J. A., 2005: Operational multivariate ocean data assimilation. Quart. J. Roy. Meteor. Soc., 131, 3583-3604, doi:10.1256/qj.05.105. 
Dare, R. A., and J. L. McBride, 2011: Sea surface temperature response to tropical cyclones. Mon. Wea. Rev., 139, 3798-3808, doi:10.1175/MWR-D-10-05019.1.

D'Asaro, E. A., T. B. Sanford, P. P. Niiler, and E. J. Terrill, 2007: Cold wake of Hurricane Frances. Geophys. Res. Lett., 34, L15609, doi:10.1029/2007GL030160.

Delworth, T. L., and Coauthors, 2012: Simulated climate and climate change in the GFDL CM2.5 high-resolution coupled climate model. J. Climate, 25, 2755-2781, doi:10.1175/ JCLI-D-11-00316.1.

Emanuel, K. A., 2001: Contribution of tropical cyclones to meridional heat transport by the oceans. J. Geophys. Res., 106, 14771-14 781, doi:10.1029/2000JD900641.

Fedorov, A. V., C. M. Brierley, and K. A. Emanuel, 2010: Tropical cyclones and permanent El Niño in the early Pliocene epoch. Nature, 463, 1066-1070, doi:10.1038/nature08831.

Fox-Kemper, B., and Coauthors, 2011: Parameterization of mixed layer eddies. III: Implementation and impact in global ocean climate simulations. Ocean Modell., 39, 61-78, doi:10.1016/j.ocemod.2010.09.002.

Ginis, I., 2002: Tropical cyclone-ocean interactions. Adv. Fluid Mech. Ser., 33, 83-114.

Gordon, A. L., R. D. Susanto, and A. Ffield, 1999: Throughflow within Makassar Strait. Geophys. Res. Lett., 26, 3325-3328, doi:10.1029/1999GL002340.

Griffies, S. M., 2009: Elements of MOM4p1. GFDL Ocean Group Tech. Rep. 6, 444 pp.

, and Coauthors, 2009: Coordinated Ocean-Ice Reference Experiments (COREs). Ocean Modell., 26, 1-46, doi:10.1016/ j.ocemod.2008.08.007.

Holland, G. J., 1980: An analytic model of the wind and pressure profiles in hurricanes. Mon. Wea. Rev., 108, 1212-1218, doi:10.1175/1520-0493(1980)108<1212:AAMOTW>2.0.CO;2.

Jansen, M. F., and R. Ferrari, 2009: Impact of the latitudinal distribution of tropical cyclones on ocean heat transport. Geophys. Res. Lett., 36, L06604, doi:10.1029/2008GL036796.

,-- , and T. A. Mooring, 2010: Seasonal versus permanent thermocline warming by tropical cyclones. Geophys. Res. Lett., 37, L03602, doi:10.1029/2009GL041808.

Jullien, S., and Coauthors, 2012: Impact of tropical cyclones on the heat budget of the South Pacific Ocean.J. Phys. Oceanogr., 42, 1882-1906, doi:10.1175/JPO-D-11-0133.1.

Large, W. G., and S. G. Yeager, 2004: Diurnal to decadal global forcing for ocean and sea-ice models: The data sets and flux climatologies. NCAR Tech. Note NCAR/TN-460+STR, 105 pp., doi:10.5065/D6KK98Q6.

— and — 2009: The global climatology of an interannually varying air-sea flux data set. Climate Dyn., 33, 341-364, doi:10.1007/s00382-008-0441-3.

— J. C. McWilliams, and S. C. Doney, 1994: Oceanic vertical mixing: A review and a model with a nonlocal boundary layer parameterization. Rev. Geophys., 32, 363-403, doi:10.1029/ 94RG01872.

Levitus, S., and Coauthors, 2012: World Ocean heat content and thermosteric sea level change $(0-2000 \mathrm{~m}), 1955-2010$. Geophys. Res. Lett., 39, L10603, doi:10.1029/2012GL051106.

Lukas, R., 1988: Interannual fluctuations of the Mindanao Current inferred from sea level. J. Geophys. Res., 93, 6744-6748, doi:10.1029/JC093iC06p06744.

Manucharyan, G. E., C. M. Brierley, and A. V. Fedorov, 2011: Climate impacts of intermittent upper ocean mixing induced by tropical cyclones. J. Geophys. Res., 116, C11038, doi:10.1029/2011JC007295.
McCreary, J. P., Jr., and P. Lu, 1994: Interaction between the subtropical and equatorial ocean circulations: The subtropical cell. J. Phys. Oceanogr., 24, 466-497.

Mei, W., and C. Pasquero, 2013: Spatial and temporal characterization of sea surface temperature response to tropical cyclones. J. Climate, 26, 3745-3765, doi:10.1175/JCLI-D-12-00125.1.

— F. Primeau, J. C. McWilliams, and C. Pasquero, 2013: Sea surface height evidence for long-term warming effects of tropical cyclones on the ocean. Proc. Natl. Acad. Sci. USA, 110, 15 207-15210, doi:10.1073/pnas.1306753110.

Moon, I.-J., I. Ginis, T. Hara, and B. Thomas, 2007: A physicsbased parameterization of air-sea momentum flux at high wind speeds and its impact on hurricane intensity predictions. Mon. Wea. Rev., 135, 2869-2878, doi:10.1175/MWR3432.1.

Park, J. J., Y.-O. Kwon, and J. F. Price, 2011: Argo array observation of ocean heat content changes induced by tropical cyclones in the North Pacific. J. Geophys. Res., 116, C12025, doi:10.1029/2011JC007165.

Pasquero, C., and K. A. Emanuel, 2008: Tropical cyclones and transient upper-ocean warming. J. Climate, 21, 149-162, doi:10.1175/2007JCLI1550.1.

Powell, M. D., P. J. Vickery, and T. A. Reinhold, 2003: Reduced drag coefficient for high wind speeds in tropical cyclones. Nature, 422, 279-283, doi:10.1038/nature01481.

Price, J. F., 1981: Upper ocean response to a hurricane. J. Phys. Oceanogr., 11, 153-175, doi:10.1175/1520-0485(1981)011<0153: UORTAH $>2.0 . \mathrm{CO} ; 2$.

_ J. Morzel, and P. P. Niiler, 2008: Warming of SST in the cool wake of a moving hurricane. J. Geophys. Res., 113, C07010, doi:10.1029/2007JC004393.

Qu, T., and R. Lukas, 2003: The bifurcation of the North Equatorial Current in the Pacific. J. Phys. Oceanogr., 33, 5-18, doi:10.1175/1520-0485(2003)033<0005:TBOTNE $>2.0$. CO;2.

Reynolds, R. W., T. M. Smith, C. Liu, D. B. Chelton, K. S. Casey, and M. G. Schlax, 2007: Daily high-resolution-blended analyses for sea surface temperature. J. Climate, 20, 5473-5496, doi:10.1175/2007JCLI1824.1.

Rothstein, L. M., R.-H. Zhang, A. J. Busalacchi, and D. Chen, 1998: A numerical simulation of the mean water pathways in the subtropical and tropical Pacific Ocean. J. Phys. Oceanogr., 28, 322-343, doi:10.1175/1520-0485(1998)028<0322: ANSOTM $>2.0 . \mathrm{CO} ; 2$.

Sanford, T. B., J. F. Price, J. B. Girton, and D. C. Webb, 2007: Highly resolved observations and simulations of the ocean response to a hurricane. Geophys. Res. Lett., 34, L13604, doi:10.1029/2007GL029679.

Scoccimarro, E., and Coauthors, 2011: Effects of tropical cyclones on ocean heat transport in a high-resolution coupled general circulation model. J. Climate, 24, 4368-4384, doi:10.1175/ 2011JCLI4104.1.

Sriver, R. L., and M. Huber, 2007: Observational evidence for an ocean heat pump induced by tropical cyclones. Nature, 447, 577-580, doi:10.1038/nature05785.

$\longrightarrow$, and -2010 : Modeled sensitivity of upper thermocline properties to tropical cyclone winds and possible feedbacks on the Hadley circulation. Geophys. Res. Lett., 37, L08704, doi:10.1029/2010GL042836.

,$- \ldots$, and J. Nusbaumer, 2008: Investigating tropical cycloneclimate feedbacks using the TRMM Microwave Imager and the Quick Scatterometer. Geochem. Geophys. Geosyst., 9, Q09V11, doi:10.1029/2007GC001842.

- — - and L. Chafik, 2013: Excitation of equatorial Kelvin and Yanai waves by tropical cyclones in an ocean general 
circulation model. Earth Syst. Dyn., 4, 1-10, doi:10.5194/ esd-4-1-2013.

Stommel, H., 1979: Determination of water mass properties of water pumped down from the Ekman layer to the geostrophic flow below. Proc. Natl. Acad. Sci. USA, 76, 3051-3055, doi:10.1073/pnas.76.7.3051.

Trahan, S., and L. Sparling, 2012: An analysis of NCEP tropical cyclone vitals and potential effects on forecasting models. Wea. Forecasting, 27, 744-756, doi:10.1175/ WAF-D-11-00063.1.

Vincent, E. M., M. Lengaigne, G. Madec, J. Vialard, G. Samson, N. C. Jourdain, C. E. Menkes, and S. Jullien, 2012a: Processes setting the characteristics of sea surface cooling induced by tropical cyclones. J. Geophys. Res., 117, C02020, doi:10.1029/ 2011JC007396.

, - - J. Vialard, G. Madec, N. C. Jourdain, and S. Masson, 2012b: Assessing the oceanic control on the amplitude of sea surface cooling induced by tropical cyclones. J. Geophys. Res., 117, C05023, doi:10.1029/2011JC007705.

, G. Madec, M. Lengaigne, J. Vialard, and A. Koch-Larrouy, 2013: Influence of tropical cyclones on sea surface temperature seasonal cycle and ocean heat transport. Climate Dyn., 41, 2019-2038, doi:10.1007/s00382-012-1556-0.

Willoughby, H. E., R. W. R. Darling, and M. E. Rahn, 2006: Parametric representation of the primary hurricane vortex. Part II: A new family of sectionally continuous profiles. Mon. Wea. Rev., 134, 1102-1120, doi:10.1175/MWR3106.1.

Yablonsky, R. M., and I. Ginis, 2009: Limitation of one-dimensional ocean models for coupled hurricane-ocean model forecasts. Mon. Wea. Rev., 137, 4410-4419, doi:10.1175/2009MWR2863.1.

Zhang, S., M. J. Harrison, A. Rosati, and A. Wittenberg, 2007: System design and evaluation of coupled ensemble data assimilation for global oceanic climate studies. Mon. Wea. Rev., 135, 3541-3564, doi:10.1175/MWR3466.1. 